This is an electronic reprint of the original article. This reprint may differ from the original in pagination and typographic detail.

Author(s): Tatikonda, Rajendhraprasad; Kalenius, Elina; Haukka, Matti

Title: $\quad$ Synthesis and Characterization of Zwitterionic Zn(II) and $\mathrm{Cu}(\mathrm{II})$ Coordination Compounds with Ring-substituted 2,2-Biimidazole Derivatives

Year: $\quad 2016$

Version:

Please cite the original version:

Tatikonda, R., Kalenius, E., \& Haukka, M. (2016). Synthesis and Characterization of Zwitterionic Zn(II) and Cu(II) Coordination Compounds with Ring-substituted 2,2Biimidazole Derivatives. Inorganica Chimica Acta, 453, 298-304. https://doi.org/10.1016/j.ica.2016.08.015

All material supplied via JYX is protected by copyright and other intellectual property rights, and duplication or sale of all or part of any of the repository collections is not permitted, except that material may be duplicated by you for your research use or educational purposes in electronic or print form. You must obtain permission for any other use. Electronic or print copies may not be offered, whether for sale or otherwise to anyone who is not an authorised user. 


\section{Accepted Manuscript}

Synthesis and Characterization of Zwitterionic $\mathrm{Zn}(\mathrm{II})$ and $\mathrm{Cu}(\mathrm{II})$ Coordination Compounds with Ring-substituted 2,2’-Biimidazole Derivatives

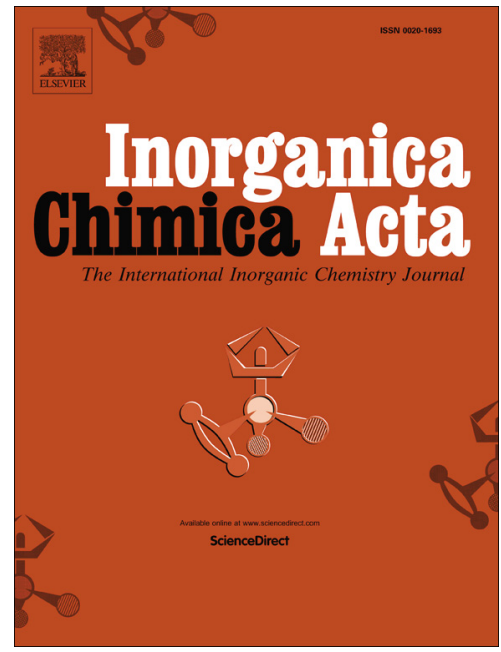

To appear in: $\quad$ Inorganica Chimica Acta

Received Date: $\quad 29$ March 2016

Revised Date: $\quad 16$ July 2016

Accepted Date: $\quad 8$ August 2016

Please cite this article as: R. Tatikonda, E. Kalenius, M. Haukka, Synthesis and Characterization of Zwitterionic $\mathrm{Zn}$ (II) and $\mathrm{Cu}(\mathrm{II})$ Coordination Compounds with Ring-substituted 2,2'-Biimidazole Derivatives, Inorganica Chimica Acta (2016), doi: http://dx.doi.org/10.1016/j.ica.2016.08.015

This is a PDF file of an unedited manuscript that has been accepted for publication. As a service to our customers we are providing this early version of the manuscript. The manuscript will undergo copyediting, typesetting, and review of the resulting proof before it is published in its final form. Please note that during the production process errors may be discovered which could affect the content, and all legal disclaimers that apply to the journal pertain. 


\title{
Synthesis and Characterization of Zwitterionic $\mathrm{Zn}$ (II) and $\mathrm{Cu}(\mathrm{II})$ Coordination Compounds with Ring-substituted 2,2'-Biimidazole Derivatives
}

\author{
Rajendhraprasad Tatikonda, Elina Kalenius and Matti Haukka* \\ Department of Chemistry, University of Jyväskylä, P.O.Box 35, FI-40014 University of Jyväskylä, Finland \\ E-mail: matti.o.haukka@jyu.fi
}

\begin{abstract}
Zwitterionic coordination compounds with strongly asymmetrical charge distribution were synthesized and characterized. Ring-substituted biimidazoles were used as the primary ligands for $\mathrm{Zn}$ and $\mathrm{Cu}$ compounds. Formation of Zwitterionic coordination compound was found to be strongly dependent on the $\mathrm{pH}$ of the reaction medium as well as on the ring and nitrogen substituents of the ligand. Reaction of the Df- $\mathrm{R}_{2}$ biim $\left(\right.$ Df-R ${ }_{2}$ biim $=$ 2,2'-bi-1R-imidazole-5,5'-dicarboxaldehyde, $\mathrm{R}=\mathrm{Me}$, Et or $\mathrm{Pr}$ ) with $\mathrm{ZnCl}_{2}$ in neutral conditions led to binuclear compounds $\left[\mathrm{Zn}_{2} \mathrm{Cl}_{4}\left(\mathrm{Df}-\mathrm{R}_{2} \text { biim }\right)_{2}\right]$ with two bridging ligands (1a-c). Reaction with $\mathrm{CuCl}_{2} \cdot 2 \mathrm{H}_{2} \mathrm{O}$ gave neutral mononuclear compound $\left[\mathrm{CuCl}_{2}\right.$ (Df-Me2biim)] (1d) with chelating biimidazole ligand. In acidic conditions $(\mathrm{pH}=3-4)$ the imidazole nitrogens were either fully or partially protonated, which prevented the bidentate coordination of the ligands. Furthermore, aldehyde substituents of Df-R biim ligands were involved in acetal formation with methanol solvent. Under acidic conditions the primary products were either ion pairs $\left[\mathrm{MCl}_{4}\right]\left[\mathrm{C}_{14} \mathrm{H}_{24} \mathrm{~N}_{4} \mathrm{O}_{4}\right](\mathrm{M}=\mathrm{Zn} \mathrm{3a}, \mathrm{M}=\mathrm{Cu} \mathbf{3 b})$ with fully protonated $\mathrm{H}_{2} \mathrm{~L}^{2+}$ counter cation or desired Zwitterionic coordination compounds [ $\left.\mathrm{ZnCl}_{3}\left(\mathrm{C}_{16} \mathrm{H}_{27} \mathrm{~N}_{4} \mathrm{O}_{4}\right)\right](\mathbf{2 a}), \quad\left[\mathrm{ZnCl}_{3}\left(\mathrm{C}_{18} \mathrm{H}_{31} \mathrm{~N}_{4} \mathrm{O}_{4}\right)\right]$ (2b), $\left[\mathrm{CuCl}_{3}\left(\mathrm{C}_{16} \mathrm{H}_{27} \mathrm{~N}_{4} \mathrm{O}_{4}\right)\right](\mathbf{2 c})$, or $\left[\mathrm{CuCl}_{3}\left(\mathrm{C}_{18} \mathrm{H}_{31} \mathrm{~N}_{4} \mathrm{O}_{4}\right)\right]$ (2d) with partially protonated monodentate $\mathrm{HL}^{+}$ ligand. Zwitterions were obtained only with ligands having both aldehyde groups as ring-substituents and longer alkyl chains (ethyl or propyl) as $N$-substituents. In other cases ion pairs were formed as final products. Zwitterions were found to decompose in alcoholic solutions. In methanol solution, Zwitterionic compounds released neutral ligand and $\mathrm{HZnCl}_{3}$. All main products were characterized by $\mathrm{NMR}$, elemental analysis and single-crystal X-ray diffraction.
\end{abstract}

\section{Keywords.}

Zinc $\bullet$ Copper $\bullet$ Biimidazole $\bullet$ Crystal structures $\bullet$ Zwitterionic and Non-coordinated compounds 


\section{Introduction.}

Imidazole is an important aromatic N-heterocyclic compound because of its significant role in biosystems and its versatile coordination ability. ${ }^{[1]}$ The 2,2'-biimidazole molecule, $\mathrm{H}_{2}$ biim, is one of the most useful dimeric analogue of imidazole and well known ligand for transition metals. Compounds containing $\mathrm{H}_{2}$ biim moiety have been the focus of several investigations due to their biological and catalytic activity. ${ }^{2]}$ Anti-protozoal, ${ }^{[2 \mathrm{~d}]}$ anti-tuberculosis, ${ }^{[2 \mathrm{e}]}$ anti-cancer, ${ }^{[2 \mathrm{f}]}$ and cardiotonic, ${ }^{[2 \mathrm{~g}]}$ properties are examples of pharmacological functionalities of biimidazole based compounds. The conjugate polymers of imidazole and biimidazole containing metal compounds exhibit outstanding sensing properties to metal ions, anions, nitric oxide and amino acids. ${ }^{[3]}$ In $\mathrm{H}_{2}$ biim, two imidazole rings are capable to adopt coplanar orientation when the ligand reacts with a metal cation. This favors chelation as the primary coordination mode. ${ }^{[4]}$ However, few exceptions, where $\mathrm{H}_{2}$ biim behaves as a bridging ligand in binuclear and polynuclear compounds, are also known. ${ }^{[5]}$ If the $\mathrm{N}-\mathrm{H}$ hydrogens are replaced with bulkier groups, chelation is less likely. Therefore, $N$ substituted $\mathrm{R}_{2}$ biim moieties are more commonly acting as bridging ligands in binuclear, ${ }^{[6]}$ oligonuclear or polynuclear ${ }^{[7]}$ compounds. So far, only few literature precedence exist of mononuclear compounds where 1,1'-dimethyl-2,2'-biimidazole, $\mathrm{Me}_{2}$ biim involved in chelation with the metal ion. ${ }^{[8]}$

Coordination modes of unsubstituted biimidazole vary from monodentate to tetradentate depending on the reaction conditions and level of protonation (Fig. 1). In neutral medium the most common coordination mode of $\mathrm{H}_{2}$ biim is bidentate chelating bonding (Fig. 1a). ${ }^{[9]}$ In this mode the protonated nitrogens are available for $\mathrm{H}$-bonding as $\mathrm{H}$-bond donors. ${ }^{\left[{ }^{9]}\right.}$ Removal of $\mathrm{N}-\mathrm{H}$ protons produces typically tridentate (mono-deprotonated biimidazole, $\mathrm{Hbiim}^{-}{ }^{[10]}{ }^{[0]}$ or tetradentate (fully deprotonated biimidazole, biim $\left.{ }^{2}\right)^{[11]}$ ligands (Fig. 1b,c). Basic medium usually favors these two coordination modes. In acidic medium biimidazole can be protonated to $\mathrm{H}_{3}$ biim ${ }^{+}$or $\mathrm{H}_{4}$ biim $^{2+}$. The cationic $\mathrm{H}_{3}$ biim $^{+}$(Fig. 1d) favors monodentate coordination. $\mathrm{In}_{4}$ biim ${ }^{2+}$ (Fig. 1e) there are no available nitrogens for coordination and therefore $\mathrm{H}_{4}$ biim $^{2+}$ is usually acting as counter cation in ionic systems.

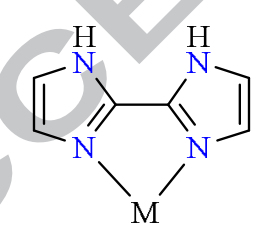

(a)

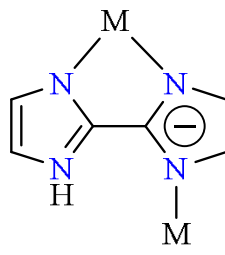

(b)

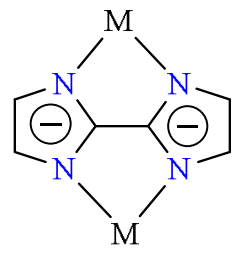

(c)

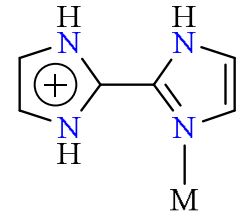

(d)

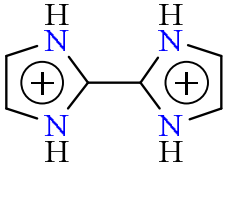

(e)

Figure 1. Coordination modes of H2biim (a) chelating (b) chelating-bridging (c) monodentate and ionic

The ring substituents (Fig. 2) have strong impact on physical and chemical properties of the biimidazole molecule. Ring substitution opens up a route for fine-tuning the properties of the ligand. However, only limited number of such biimidazole derivatives have been synthesized and structurally characterized and even fewer of those have been used as ligands in metal compounds. ${ }^{[14,15]}$ 


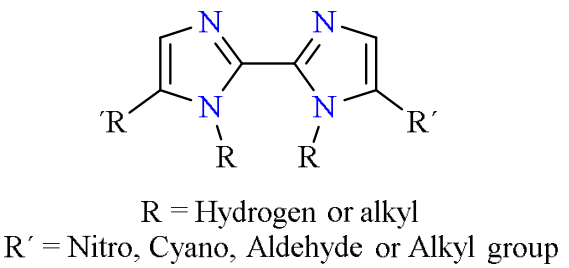

Figure 2. Ring -substituted (R') and $N$-substituted (R) 2,2'-Biimidazole.

This paper describes the synthesis and structural characterization of a series of zinc and copper coordination compounds with ring-substituted Df- $\mathrm{R}_{2}$ biim $\left(2,2^{\prime}\right.$-bi-1R-imidazole-5, $5^{\prime}$-dicarboxaldehyde, $\mathrm{R}=$ $\mathrm{Me}, \mathrm{Et}$ or Pr) derivatives. The goal was to use different ring substituents and the level of protonation as tools for preparation of polar and especially Zwitterionic coordination compounds. The products were characterized by NMR, IR, elemental analysis, molar conductivity and single crystal X-ray crystallography. The potential reaction route to Zwitterionic products is also briefly discussed.

\section{Experimental Section}

2.1 General Considerations. $\mathrm{R}_{2}$ biim and ring-substituted 2,2'-biimidazole derivatives, 2,2'-bi-1alkylimidazole-5,5'-dicarboxaldehyde (Df- $\mathrm{R}_{2}$ biim) were synthesized by following literature methods (see ESI) ${ }^{[16,17]}$ All other chemicals were obtained from commercial source. The NMR spectra $\left({ }^{1} \mathrm{H}\right.$ and $\left.{ }^{13} \mathrm{C}\right)$ of ligands were recorded on Bruker Avance DRX 400 NMR spectrometer and chemical shifts were expressed in ppm. Elemental analyses were performed on VarioEL elemental analyzer. Molar conductivity experiments were performed by using handylab LF11 manufactured by Scott.

\subsection{Synthesis}

\subsubsection{Synthesis of Binuclear $\mathrm{Zn}$ (II) and Mononuclear $\mathrm{Cu}$ (II) coordination compounds with $\mathrm{Df}-\mathrm{R}_{2} \mathrm{biim}$} $(\mathrm{R}=\mathrm{Me}, \mathrm{Et}$ or $\mathrm{Pr})(\mathbf{1 a - f})$

A mixture of metal chloride $\left(\mathrm{ZnCl}_{2}\right.$ or $\left.\mathrm{CuCl}_{2} \cdot 2 \mathrm{H}_{2} \mathrm{O}\right)$ and Df- $\mathrm{R}_{2}$ biim (1:1) in methanol was stirred for 30 min to produce binuclear $\mathrm{Zn}(\mathrm{II})$ (white precipitate) and mononuclear $\mathrm{Cu}(\mathrm{II})$ compounds (blue precipitate). The compound was collected through filtration, washed with cold methanol and dried under vacuum. X-ray quality crystals were obtained with solvent diffusion process of methanolic metal solution to the ligand solution in chloroform. The yield was calculated based on metal salt.

[ $\left.\mathbf{Z n}_{2} \mathbf{C l}_{4}\left(\mathbf{C}_{10} \mathbf{H}_{10} \mathbf{N}_{4} \mathbf{O}_{2}\right)_{2}\right]$ 1a. Yield: 82\%. ${ }^{1} \mathrm{H}$ NMR ( $\delta, 400 \mathrm{MHz}$, DMSO-D6): 4.18 (s, 12H), $8.10(\mathrm{~s}, 4 \mathrm{H}), 9.86$ (s, 4H). ${ }^{13} \mathrm{C}$ NMR $(\delta, 100 \mathrm{MHz}$, DMSO-D6): 34.35, 132.63, 141.94, 142.02, 180.96. Anal. Calcd for $\mathrm{C}_{20} \mathrm{H}_{20} \mathrm{~N}_{8} \mathrm{O}_{4} \mathrm{Zn}_{2} \mathrm{Cl}_{4} . \mathrm{CH}_{3} \mathrm{OH}$ (741.038): C, 34.04; H, 3.26; N, 15.12. Found: C, 33.84; H, 3.34; N, 14.80. IR (v, cm-1): $1686(\mathrm{CO})$. 
$\left[\mathbf{Z n}_{2} \mathbf{C l}_{4}\left(\mathbf{C}_{12} \mathbf{H}_{14} \mathbf{N}_{4} \mathbf{O}_{2}\right)_{2}\right]$ 1b. Yield: 80\%. ${ }^{1} \mathrm{H}$ NMR ( $\delta, 400 \mathrm{MHz}$, DMSO-D6): 1.33 (t, 12H), 4.69 (q, 8H), 8.13 (s, 4H), 9.84 (s, 4H). ${ }^{13} \mathrm{C}$ NMR ( $\delta, 100 \mathrm{MHz}$, DMSO-D6): 16.12, 41.81, 131.99, 141.30, 143.08, 180.53. Anal. Calcd for $\mathrm{C}_{24} \mathrm{H}_{28} \mathrm{~N}_{8} \mathrm{O}_{4} \mathrm{Zn}_{2} \mathrm{Cl}_{4}$ (765.102): C, 37.68; H, 3.69; N, 14.65. Found: C, 37.22; H, 3.76; N, 14.27. IR ( $(v, \mathrm{~cm}-1)$ : $1686(\mathrm{CO})$.

$\left[\mathbf{Z n}_{2} \mathbf{C l}_{4}\left(\mathbf{C}_{14} \mathbf{H}_{18} \mathbf{N}_{\mathbf{4}} \mathbf{O}_{2}\right)_{2}\right]$ 1c. Yield: 87\%. ${ }^{1} \mathrm{H}$ NMR ( $\left.\delta, 400 \mathrm{MHz}, \mathrm{DMSO}-\mathrm{D} 6\right): 0.79$ (t, 12H), 1.66-1.75 (m, $8 \mathrm{H}), 4.69(\mathrm{t}, 8 \mathrm{H}), 8.14(\mathrm{~s}, 4 \mathrm{H}), 9.84(\mathrm{~s}, 4 \mathrm{H}) .{ }^{13} \mathrm{C}$ NMR $(\delta, 100 \mathrm{MHz}$, DMSO-D6): 10.58, 23.75, 47.46, 132.22, 141.56, 142.95, 180.64. Anal. Calcd for $\mathrm{C}_{28} \mathrm{H}_{36} \mathrm{~N}_{8} \mathrm{O}_{4} \mathrm{Zn}_{2} \mathrm{Cl}_{4}$ (821.209): C, 40.95; H, 4.42; N, 13.64 . Found: C, 40.68; H, 4.38; N, 13.34. IR (v, cm-1): 1682 (CO)

[CuCl $\left.\mathbf{C u}_{2}\left(\mathbf{C}_{10} \mathbf{H}_{10} \mathbf{N}_{4} \mathbf{O}_{2}\right)\right]$ 1d. Yield: $74 \%$. Anal. Calcd for $\mathrm{C}_{10} \mathrm{H}_{10} \mathrm{~N}_{4} \mathrm{O}_{2} \mathrm{CuCl}_{2}$ (352.664): C, 34.06; H, 2.86; N, 15.89. Found: C, 34.12; H, 2.92 N, 16.02. IR (v, cm-1): 1686 (CO).

[CuCl $\left.\mathbf{C u}_{2}\left(\mathbf{C}_{12} \mathbf{H}_{14} \mathbf{N}_{4} \mathbf{O}_{2}\right)\right]$ 1e. Yield: $78 \%$. Anal. Calcd for $\mathrm{C}_{12} \mathrm{H}_{14} \mathrm{~N}_{4} \mathrm{O}_{2} \mathrm{CuCl}_{2}$ (380.717): C, 37.86; H, 3.71; N, 14.72. Found: C, 37.56; H, 3.66; N, 14.44. IR (v, cm-1): 1687 (CO).

[CuCl $\left.\mathbf{C u}_{2}\left(\mathbf{C}_{14} \mathbf{H}_{18} \mathbf{N}_{4} \mathbf{O}_{2}\right)\right]$ 1f. Yield: 77\%. Anal. Calcd for $\mathrm{C}_{14} \mathrm{H}_{18} \mathrm{~N}_{4} \mathrm{O}_{2} \mathrm{CuCl}_{2}$ (408.770): C, 41.14; H, 4.44; N, 13.71. Found: C, 40.80; H, 4.42; N, 13.86. IR (v, cm-1): 1686 (CO).

\subsubsection{Synthesis of Zwitterionic coordination compounds $2 a-d$}

A binuclear (1b or 1c, $0.1 \mathrm{mmol}$ ) or mononuclear (1e or 1f, $0.1 \mathrm{mmol}$ ) coordination compounds were dissolved in $2 \mathrm{~mL}$ of methanol by adding 5-6 drops of $\mathrm{Conc}$. $\mathrm{HCl}(\mathrm{pH}=3-4)$. The resulting solution was filtered off and the final crystalline product was obtained by slow evaporation of the solvent. After couple of days, colorless crystals for $\mathrm{Zn}^{2+}$ or blue colored crystals for $\mathrm{Cu}^{2+}$ were formed in filtrate at room temperature. During the reaction aldehyde groups from the ligand was involved in acetal formation in presence of methanolic $\mathrm{HCl}$ solutions. The yield was calculated based on metal salt.

[ $\left.\mathrm{ZnCl}_{3}\left(\mathbf{C}_{16} \mathrm{H}_{27} \mathbf{N}_{4} \mathbf{O}_{4}\right)\right]$ (2a). Yield: $62 \%$. Anal. Calcd for $\mathrm{C}_{16} \mathrm{H}_{27} \mathrm{~N}_{4} \mathrm{O}_{4} \mathrm{ZnCl}_{3} \cdot \mathrm{CH}_{3} \mathrm{OH}$ (543.191): C, 37.59; H, 5.75; N, 10.31. Found: C, 37.36; H, 5.49; N, 10.45 .

[ $\left.\mathrm{ZnCl}_{3}\left(\mathbf{C}_{18} \mathrm{H}_{31} \mathbf{N}_{4} \mathbf{O}_{4}\right)\right]$ (2b). Yield: $60 \%$. Anal. Calcd for $\mathrm{C}_{18} \mathrm{H}_{31} \mathrm{~N}_{4} \mathrm{O}_{4} \mathrm{ZnCl}_{3} . \mathrm{CH}_{3} \mathrm{OH}$ (571.244): C, 39.95; H, 6.18; N, 9.81. Found: C, 39.69; H, 5.96; N, 9.88.

$\left[\mathrm{CuCl}_{3}\left(\mathrm{C}_{16} \mathbf{H}_{27} \mathbf{N}_{4} \mathbf{O}_{4}\right)\right]$ (2c). Yield: 58\%. Anal. Calcd for $\mathrm{C}_{16} \mathrm{H}_{27} \mathrm{~N}_{4} \mathrm{O}_{4} \mathrm{CuCl}_{3}$ (509.32): C, 37.73; H, 5.34; N, 11.00. Found: C, 37.62; H, 5.39; N, 11.02 .

[CuCl $\left.\mathbf{C u}_{3}\left(\mathbf{C}_{18} \mathrm{H}_{31} \mathbf{N}_{4} \mathbf{O}_{4}\right)\right]$ (2d). Yield: 57\%. Anal. Calcd for $\mathrm{C}_{18} \mathrm{H}_{31} \mathrm{~N}_{4} \mathrm{O}_{4} \mathrm{CuCl}_{3}$ (537.37): C, 40.23; H, 5.81; N, 10.43. Found: C, 40.42; H, 5.92; N, 10.39 .

$\mathbf{2 b 1}$ is hydrolyzed product of $\mathbf{2 b}$, where acetal groups are hydrolyzed back to aldehyde. Compound $\mathbf{5}$ was synthesized following the same procedure but using $\mathrm{HBr}$ instead of $\mathrm{HCl}$. Compound $2 \mathrm{~b} 1$ and $\mathbf{5}$ was characterized only by single-crystal X-ray crystallography (For single crystal x-ray structure see ESI). 


\subsubsection{Synthesis of $\mathrm{Cu}(\mathrm{II})$ and $\mathrm{Zn}(\mathrm{II})$ ion pairs with $\mathrm{Df}-\mathrm{Me}_{2}$ biim (3ab)}

Syntheses of ionic compounds were carried out by dissolving binuclear $\left[\mathrm{Zn}_{2} \mathrm{Cl}_{4}\left(\mathrm{Df}-\mathrm{Me}_{2} \mathrm{Biim}\right)_{2}\right]$ (1a, 0.1 mmol) or mononuclear $\left[\mathrm{CuCl}_{2}\left(\mathrm{Df}-\mathrm{Me}_{2} \mathrm{Biim}\right)\right](\mathbf{1 d}, 1 \mathrm{mmol})$ in $2 \mathrm{~mL}$ of methanol. The solution was made acidic by adding 5-6 drops of Conc. HCl. After couple of days, colorless or blue crystals were obtained in filtrate. The aldehyde group from the ligand was involved in acetal formation.

$\left[\mathbf{Z n C l}_{4}\right]\left[\mathbf{C}_{\mathbf{1 4}} \mathbf{H}_{\mathbf{2 4}} \mathbf{N}_{4} \mathbf{O}_{4}\right]$ (3a). Yield: 64\%. Anal. Calcd for $\mathrm{C}_{14} \mathrm{H}_{24} \mathrm{~N}_{4} \mathrm{O}_{4} \mathrm{ZnCl}_{4}: \mathrm{C}, 32.36 ; \mathrm{H}, 4.66 ; \mathrm{N}, 10.78$. Found: C, 32.99; H, 4.72; N, 11.85 .

$\left[\mathrm{CuCl}_{4}\right]\left[\mathbf{C}_{\mathbf{1 4}} \mathrm{H}_{24} \mathbf{N}_{4} \mathrm{O}_{4}\right](\mathbf{3 b})$. Yield: 54\%. Anal. Calcd for $\mathrm{C}_{14} \mathrm{H}_{24} \mathrm{~N}_{4} \mathrm{O}_{4} \mathrm{CuCl}_{4}$ : C, 32.48; H, 4.67; N, 10.82 . Found: C, 33.10; H, 4.80; N, 10.98.

Ion pairs $\left(\left[\mathrm{ZnCl}_{4}\right]^{-2}\left[\mathrm{C}_{10} \mathrm{H}_{16} \mathrm{~N}_{4}\right]^{2+}: \mathbf{4 a}\right.$ and $\left.\left[\mathrm{ZnCl}_{4}\right]^{-2}\left[\mathrm{C}_{12} \mathrm{H}_{20} \mathrm{~N}_{4}\right]^{2+}: \mathbf{4 b}\right)$ were synthesized from the reaction of $\mathrm{ZnCl}_{2}$ with $\mathrm{R}_{2} \mathrm{Biim}(\mathrm{R}=\mathrm{Et}$ or $\mathrm{Pr})$ in acidic medium $(\mathrm{pH}=3-4)$. These compounds were characterized only by single crystal X-ray crystallography (see ESI).

\subsection{X-ray Crystallography}

X-ray Structure Determination. The crystals of 1-5 were immersed in cryo-oil, mounted in a MiTeGen loop and measured at 120-123 K. The X-ray diffraction data were collected on an Agilent Technologies Supernova or a Bruker AXS Kappa Apex diffractometer using Mo $\mathrm{K} \alpha$ or $\mathrm{Cu} \mathrm{K} \alpha$ radiation. The CrysAlisPro ${ }^{[18]}$ or Denzo-Scalepack ${ }^{[19]}$ program packages were used for cell refinements and data reductions. Structures were solved by charge flipping method using SUPERFLIP ${ }^{[20]}$ program or by direct methods using SHELXS-2014 ${ }^{[21]}$ program. An analytical, Gaussian, or multi-scan $\left(\right.$ CrysAlisPro ${ }^{[18]}, S A D A B S^{[22]}$ ) absorption correction was applied to all data. Structural refinements were carried out using SHELXL-2014 $4^{[21]}$ or SHELXL-97 $7^{[21]}$ software. In structure 2b1, carbon atoms of some of the alkyl substituents (C9-C14) were slightly disordered but no disorder model was used in the final structure refinement. In $\mathbf{4 a}$, one of the ethyl substituents (C9C, C10C/C9D C10D) was disordered over two sites with occupancy ratio of 0.48/0.52. The carbon atoms of these disordered groups were restrained with effective standard deviation 0.01 so that their $\mathrm{U}_{\mathrm{ij}}$ components approximate to isotropic behavior. In structure 5, two of alkoxy groups (C13-C15B) were disordered over two sites with occupancy ratio of $0.57 / 0.43$. Also, $\mathrm{Br} 2$ atom was slightly disordered but no disorder model was used for the final structure refinement. Hydrogen atoms were either placed in calculated positions or located from the difference Fourier map. In all cases hydrogen atoms were refined using riding model. The crystallographic details of $\mathbf{1 b}, \mathbf{1 d}, \mathbf{2 a}, \mathbf{2 b}, \mathbf{2 c}, \mathbf{3 a}$, and $\mathbf{3 b}$ are summarized in Table S1. Crystallographic details of all other structures (4 and 5) are given in Table S3. Graph sets for intermolecular H-bonding were analyzed by using Mercury. ${ }^{[23]}$ 


\section{Results and discussion}

A series of ring-substituted 2,2'-biimidazole derivatives were synthesized by adopting literature procedure. ${ }^{[17]}$ The ligand synthesis method was slightly modified by increasing the reaction time and molar amounts of reagents used to improve the yields and selectivity towards $2,2^{\prime}$-Bi-1R-imidazole $-5,5^{\prime}$ dicarboxaldehydes (Df-R $\mathrm{R}_{2}$ biim) (see ESI). The ligands (Df- $\mathrm{R}_{2}$ biim) synthesis involves direct lithiation followed by subsequent formylation with DMF in THF solution.

Reaction of Df- $\mathrm{R}_{2}$ biim with $\mathrm{ZnCl}_{2}$ and $\mathrm{CuCl}_{2} \cdot 2 \mathrm{H}_{2} \mathrm{O}$ in methanolic solution produced neutral binuclear $\mathrm{Zn}$ (II) (1a-c) $^{[23]}$ and mononuclear $\mathrm{Cu}(\mathrm{II})$ (1d) compounds (Scheme 1). Reaction of Df- $\mathrm{R}_{2}$ biim with $\mathrm{Zn}^{2+}$ led to binuclear compounds with bridging Df- $\mathrm{R}_{2}$ biim ligands linking two tetrahedral $\mathrm{Zn}$ centers together. With $\mathrm{Cu}^{2+}$ Df-Me $\mathrm{M}_{2}$ Biim formed mononuclear square planar structure, where the imidazole derivative was chelating (1d). Unlike in structures 1a-1c, the imidazole rings in the chelating 1d structure were nearly coplanar.

Reaction of $\mathrm{Cu}^{2+}$ with ethyl and propyl substituted ligands gave solid products but no X-ray quality crystals could be obtained. These products were characterized only by elemental analysis. Because of the lack of crystal structures, detailed geometries of products 1e and $\mathbf{1 f}$ could not be confirmed. Based on literature and obtained results, it can be assumed that the structure of $\mathbf{1 e}$ and $\mathbf{1 f}$ could resemble either mononuclear copper compound $\mathbf{1 d}$ or a binuclear zinc compound 1a-c. ${ }^{[6,24]}$
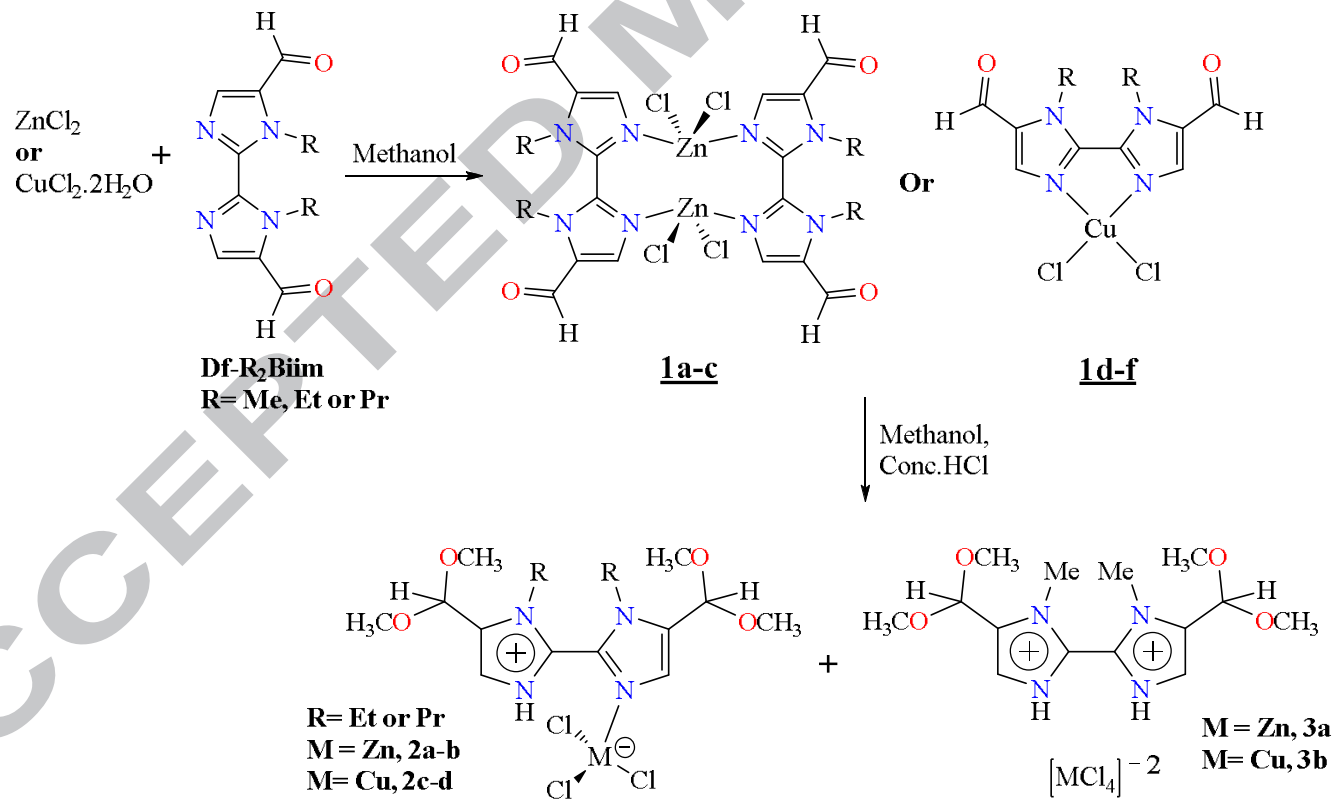

Scheme 1. Synthesis of $\mathrm{Zn}(\mathrm{II})$ and $\mathrm{Cu}(\mathrm{II})$ compounds in neutral and acidic medium.

When the compounds 1a-1f were redissolved in methanol by adding few drops of concentrated $\mathrm{HCl}(\mathrm{pH}=$ $3-4)$, either one or both metal-nitrogen bonds were broken and protonated. This led to two types of new products i.e. Zwitterionic (2a-d) coordination compounds (Scheme 1) or ion pairs of the type $\left[\mathrm{MCl}_{4}\right]^{2-}$ $\left[\mathrm{C}_{14} \mathrm{H}_{24} \mathrm{~N}_{4} \mathrm{O}_{4}\right]^{2+}(\mathbf{3 a}, \mathbf{b})$ or $\left[\mathrm{MCl}_{4}\right]^{2-}\left[\mathrm{H}_{2} \mathrm{R}_{2} \text { biim }\right]^{2+}(\mathbf{4 a}, \mathbf{b})$ depending on the substituents of the biimidazole 
ligand. Formation of Zwitterionic coordination compounds required low enough $\mathrm{pH}$ (3-4) to protonate one of the biimidazole nitrogens. In addition, the biimidazole ligand had to have aldehyde group as ring-substituents and longer alkyl chain (ethy or propyl) as $N$-substituents. The aldehyde groups were involved in acetal formation during the reaction and this was found to be crucial step to obtain Zwitterionic coordination compounds even if the detailed mechanism is not clear. On the other hand, aldehyde group alone was not enough to get Zwitterionic compounds (3a,b). The ligand also had to have longer chain alkyl groups as ringsubstituents (Fig. 3).

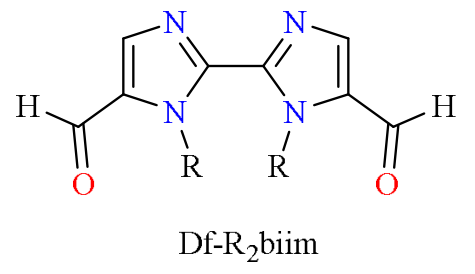

Figure 3. Ligand required for the Zwitterion formation $(\mathrm{R}=\mathrm{Et}, \mathrm{Pr})$.

If either aldehyde group or longer chain alkyl group was missing, only ion pairs were obtained (3a,b and 4a,b). Interestingly, the acetal formation was found to be reversible. When the acetal containing Zwitterion compound $\mathbf{2 b}$ was recrystallized from acetonitrile, the acetal groups were hydrolyzed back to aldehyde (2b1) due to residual water of the solvent.

The reaction of $\mathrm{ZnCl}_{2}$ with $\mathrm{Df}-\mathrm{Et}_{2} \mathrm{Biim}$ was also performed in methanolic $\mathrm{HBr}$ solution. In this reaction, the formation of the Zwitterionic compound was accompanied by exchange of $\mathrm{Cl}$ ligands with $\mathrm{Br}(\mathbf{5})$.

\section{Molar conductivity.}

The stability of the Zwitterions in solution was studied by dissolving compounds $\mathbf{2 a}$ and $\mathbf{2 b}$ in methanol and measuring the conductivity of the solutions $\left(5 \cdot 10^{-4} \mathrm{M}\right)$. The conductivities of the solutions of $2 \mathrm{a}$ and $2 \mathrm{~b}$ were found to be 52.4 and $52.7 \mu \mathrm{S} / \mathrm{cm}$ at $21^{\circ} \mathrm{C}$ respectively. Such values fall into the range of typical $1: 1$ electrolytes (the molar conductivity of $5 \cdot 10^{-4} \mathrm{M} \mathrm{KCl}$ solution in methanol was found as $52.7 \mu \mathrm{s} / \mathrm{cm}$ at $21^{\circ} \mathrm{C}$ ) indicating that the Zwitterions were decomposed. It is expected that the proton of the biimidazole is migrated to $\mathrm{Zn}$, which results in release of neutral biimidazole compounds with acetal substituents and $\mathrm{HZnCl}_{3}$ salt (Scheme 3).
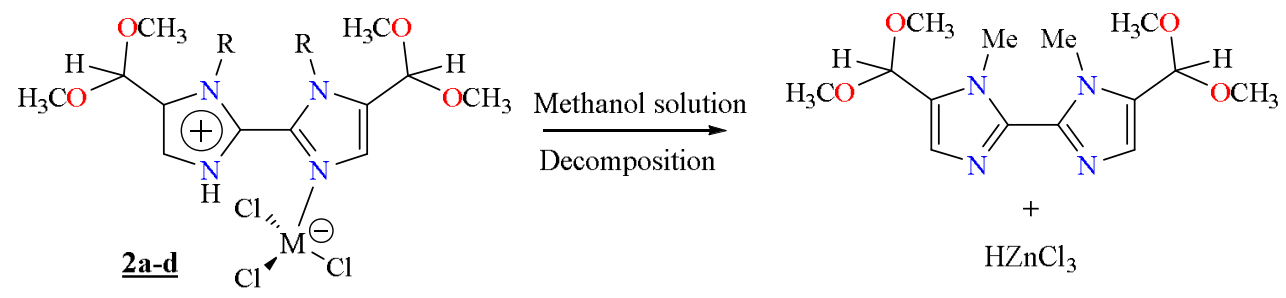

$\mathrm{HZnCl}_{3}$

Scheme 2. Decomposition of the Zwitterionic compound in methanolic solution. 
The proposed decomposition route was further supported by ${ }^{1} \mathrm{H}-\mathrm{NMR}$ and mass spectrometric analysis. In ${ }^{1} \mathrm{H}-\mathrm{NMR}$ only one ring proton signal was observed at $\delta 7.65 \mathrm{ppm}$. Mass spectra confirmed the decomposition $\left(\left[\mathrm{C}_{16} \mathrm{H}_{27} \mathrm{~N}_{4} \mathrm{O}_{4}\right]^{+}\right.$at $m / z_{\exp } 339.1892, \mathrm{~m} / z_{\text {theor }} 339.2027$; $\left[\mathrm{C}_{18} \mathrm{H}_{31} \mathrm{~N}_{4} \mathrm{O}_{4}\right]^{+}$at $\mathrm{m} / z_{\text {exp }} 367.2305, \mathrm{~m} / \mathrm{z}_{\text {theor }} 339.234$ and $\left[\mathrm{ZnCl}_{3}\right]^{-}$at $\left.\mathrm{m} / \mathrm{z}_{\exp } 168.7905, \mathrm{~m} / \mathrm{z}_{\text {theor }} 168.8363\right)$.

\subsection{Crystal Structures}

The molecular structures with the numbering schemes are shown in Figures 4-7. Crystallographic data and selected bond distances, angles are summarized in the supplementary Table S1, $\mathbf{S 2}$ and $\mathbf{S 3}$.

[ $\left.\mathbf{Z n}_{2} \mathbf{C l}_{4}\left(\mathbf{D f}-\mathbf{E t}_{2} \mathbf{B i i m}\right)_{2}\right]$ (1b). As in the case of known $\left[\mathrm{Zn}_{2} \mathrm{Cl}_{4}\left(\mathrm{Me}_{2} \mathrm{Biim}\right)_{2}\right]$ structure, ${ }^{[24]}$ the zinc atoms in $\mathbf{1 b}$ are centrosymmetrycally double-bridged by two biimidazolic nitrogens to form a binuclear compound. The planes of the imidazole rings of the ligands are nearly perpendicular with the angle of $85.67^{\circ}$. In $\mathbf{1 b}$, the typical tetrahedral coordination sphere of the $\mathrm{Zn}$ atoms are completed by two chlorido ligands. The $\mathrm{Zn}-\mathrm{N}$ $[\mathrm{Zn} 1-\mathrm{N} 2=2.064(5) \AA, \mathrm{Zn} 1-\mathrm{N} 4=2.053(2) \AA], \mathrm{Zn}-\mathrm{Cl}[\mathrm{Zn}-\mathrm{Cl} 1=2.219(3) \AA, \mathrm{Zn} 1-\mathrm{Cl} 2=2.207(5) \AA]$ distances indicate slight asymmetry in the structure and $\mathrm{Zn}-\mathrm{N}$ bond distances are almost identical to the $\left[\mathrm{Zn}_{2} \mathrm{Cl}_{4}\left(\mathrm{Me}_{2} \mathrm{Biim}\right)_{2}\right]$ structure. The $\mathrm{Zn} 1-\mathrm{N} 4$ bond length $(2.053(2) \AA)$ remains practically unchanged during conversion from the binuclear 1b to Zwitterionic 2a and Zn1-N2 bond (2.064(5) $\AA$ ) opens up allowing a third chloride ligand entering the coordination sphere of $\mathrm{Zn}$.

$\left[\mathrm{CuCl}_{2}\right.$ (Df-Me $\left.\left.\mathrm{Me}_{2} \mathrm{Bim}\right)\right]$ (1d). The copper atom in this molecule is tetra-coordinated with square planar geometry and surrounded by two chlorido ligands and two nitrogen atoms from the chelating ligand. The bite angle [N2-Cu1-N2] of the chelating biimidazole ligand is $78.96^{\circ}$ and the imidazole rings of the ligand are almost coplanar. The angle between the planes of the rings is only about $5.9^{\circ}$. The $\mathrm{Cu}-\mathrm{N}$ distances $(1.988(2)$ and 2.2261(6) $\AA$ ) are in the range of typical $\mathrm{Cu}-\mathrm{N}_{\mathrm{im}}(1.94-2.03 \AA)$ distances. ${ }^{[6,26]}$
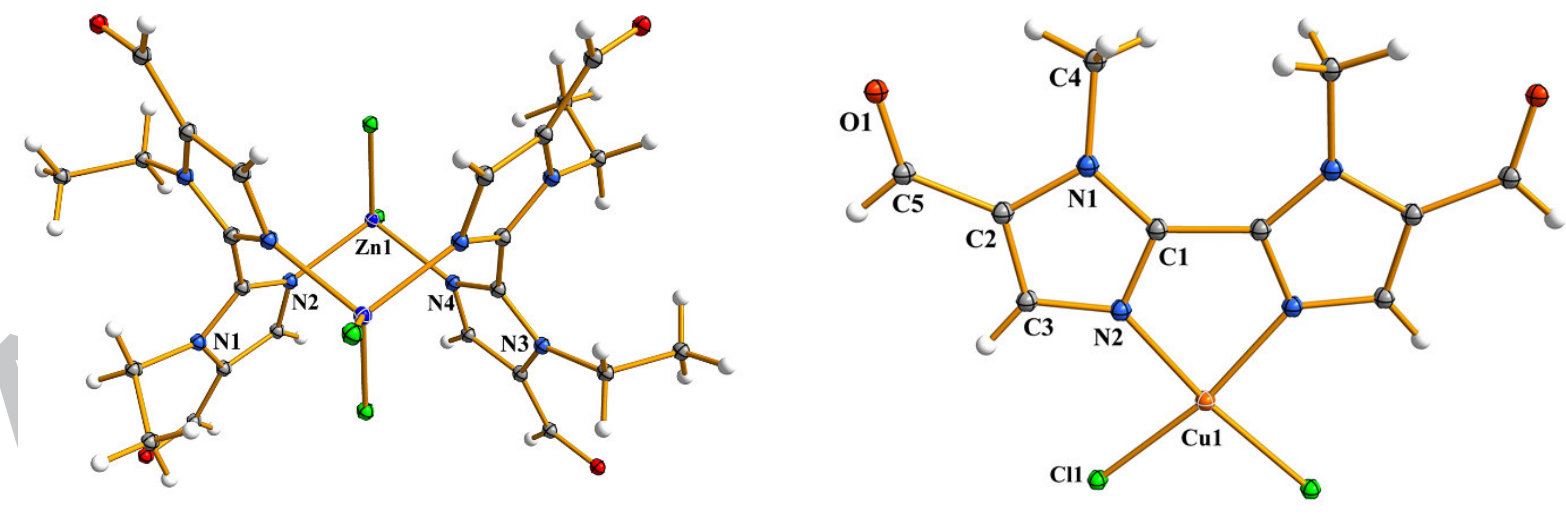

Figure 4. Molecular structure of $\mathbf{1 b}$ (Left) and 1d (right). Thermal ellipsoids are drawn at the 50\% probability level. 
$\left[\mathrm{ZnCl}_{3}\left(\mathbf{C}_{16} \mathrm{H}_{27} \mathbf{N}_{4} \mathbf{O}_{4}\right)\right]$ (2a). The coordination geometry around zinc atom is slightly distorted tetrahedron consisting of three chlorido ligands and one nitrogen atom from the singly protonated biimidazole ligand, $\left[\mathrm{C}_{16} \mathrm{H}_{27} \mathrm{~N}_{4} \mathrm{O}_{4}\right]^{+}$. The $\mathrm{Zn}-\mathrm{Cl}$ bond lengths $[\mathrm{Zn} 1-\mathrm{Cl} 1=2.242(3) \AA, \mathrm{Zn} 1-\mathrm{Cl} 2=2.260(4) \AA$ and $\mathrm{Zn} 1-\mathrm{Cl} 3=$ $2.270(6) \AA]$ show again slight asymmetry of the structure. The angle between the planes of the twoimidazole rings is about $89.3^{\circ}$. In $2 \mathrm{a}$, the intermolecular H-bonds are observed between two Zwitterionic molecules with the distance of $\mathrm{Cl} 3 \cdots \mathrm{N} 4^{\mathrm{i}}=3.144(2) \AA(\mathrm{i}=1-\mathrm{X}, 2-\mathrm{Y}, 1-\mathrm{Z})$, and the angle of $\mathrm{N}-\mathrm{H} \cdots \mathrm{Cl}=$ $154.5^{\circ}$ in $R_{2}^{2}(14)$ synthon. The $\mathrm{N} \cdots \mathrm{Cl}$ distance falls in the range of typical $\mathrm{N}-\mathrm{H} \cdots \mathrm{Cl}$ hydrogen bonds $(2.91-3.62 \AA) .{ }^{[9 d, 26 a, 27]}$

$\left[\mathrm{ZnCl}_{3}\left(\mathbf{C}_{18} \mathbf{H}_{31} \mathbf{N}_{4} \mathbf{O}_{4}\right)\right]$ (2b). The coordination sphere of $\mathrm{Zn}$ consists of three chlorido ligands and one nitrogen atom from the biimidazole ligand $\left[\mathrm{C}_{18} \mathrm{H}_{31} \mathrm{~N}_{4} \mathrm{O}_{4}\right]^{+}$as in 2a. The structure contains methanol of crystallization, which is hydrogen bonded to the protonated nitrogen of the imidazole ligand $(\mathrm{N} \cdots \mathrm{O}$ distance: $2.682 \AA$. The angle between the planes of imidazole rings is somewhat smaller $\left(78.6^{\circ}\right)$ than in $2 \mathbf{a}$, but the imidazole rings are again clearly not co-planar. During crystallization process, methanol of crystallization was trapped into the crystal voids by $\mathrm{H}$-bonds. The $\mathrm{N}-\mathrm{H}$ and $\mathrm{Cl}$ groups of the neighboring compounds were involved in intermolecular H-bonding with methanol $[\mathrm{N} \cdots \mathrm{O}=2.682(2)$ and $\mathrm{O} \cdots \mathrm{Cl}=3.229(2) \AA]$ and the angles of $\mathrm{N}-\mathrm{H} \cdots \mathrm{O}$ and $\mathrm{O}-\mathrm{H} \cdots \mathrm{Cl}$ are $164.9^{\circ}$ and $157.9^{\circ}$ respectively. Methanol solvent was acting as $\mathrm{H}-$ bonding acceptor in $\mathrm{D}^{1}{ }_{1}(2) \mathrm{a}$, donor in $\mathrm{D}^{1}{ }_{1}(2) \mathrm{b}$ and as both acceptor and donor in $R_{4}^{4}(18)$ synthons.

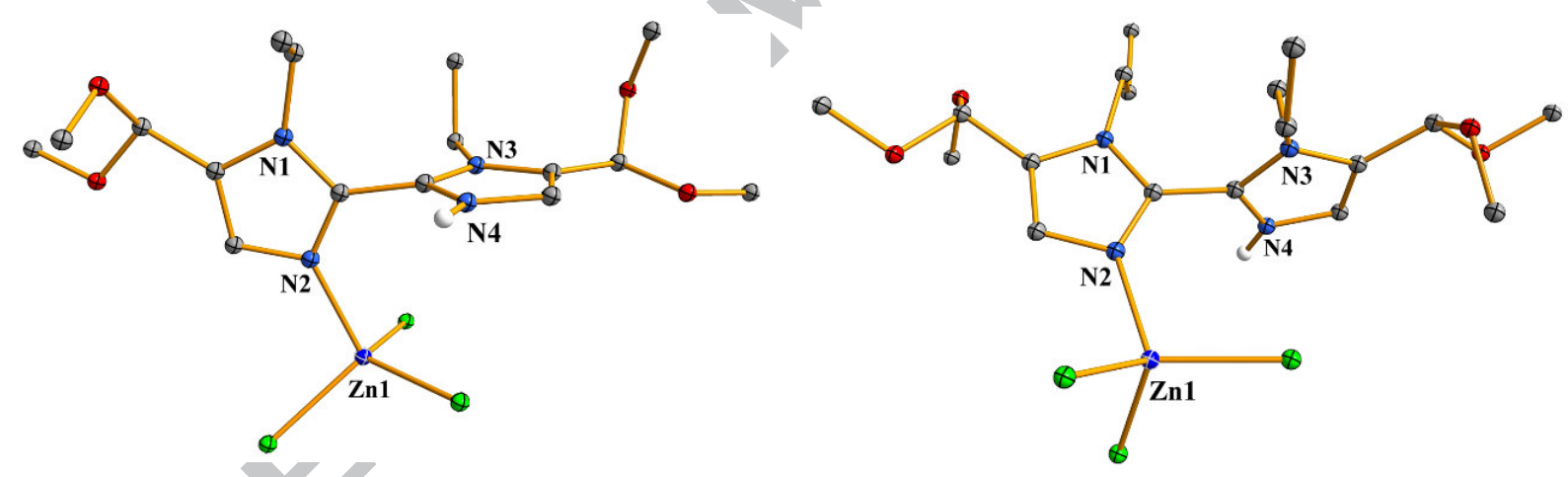



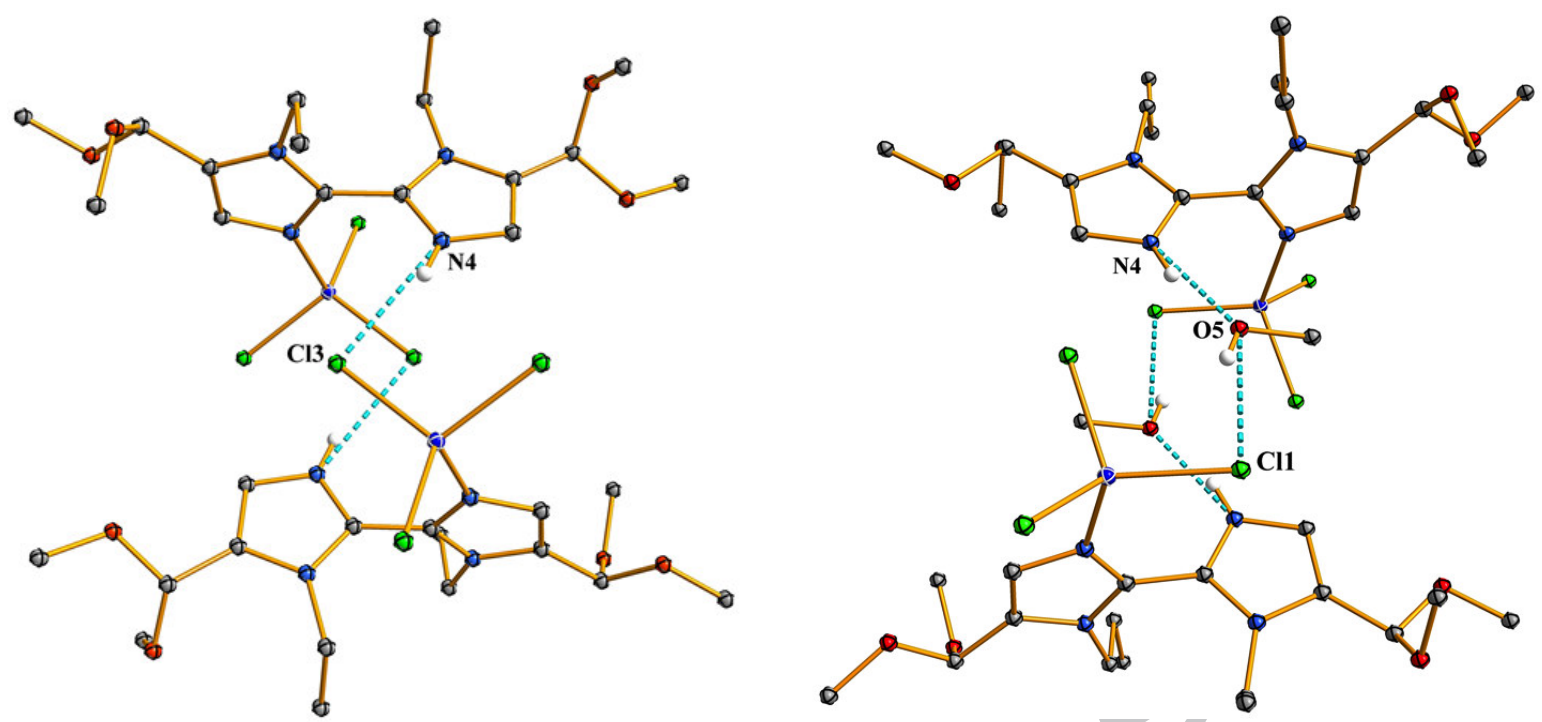

Figure 5. Molecular structure and intermolecular H-bonding in structure 2a (left) in $R_{2}^{2}(14)$ and $2 \mathbf{b}$ (right) in $R_{4}^{4}(18)$ synthons. C-H hydrogens are omitted for clarity (50\% probability ellipsoids).

$\left[\mathrm{CuCl}_{3}\left(\mathrm{C}_{16} \mathrm{H}_{27} \mathrm{~N}_{4} \mathrm{O}_{4}\right)\right]$ (2c). The copper atom in this distorted tetrahedral molecule is surrounded by three chlorido ligands and one nitrogen from the imidazole ligand, $\left[\mathrm{C}_{16} \mathrm{H}_{27} \mathrm{~N}_{4} \mathrm{O}_{4}\right]^{+}$. The $\mathrm{Cu}-\mathrm{N} 2$ distance (2.002(4) $\AA$ ) is shorter than the corresponding $\mathrm{Zn}-\mathrm{N} 2$ bond length, which is in the range of typical $\mathrm{Cu}-\mathrm{N}$ distances (1.94-2.002 $\AA$ ). The angle between the planes of the two imidazole rings is about $79.2^{\circ}$. Similarly to 2a, intermolecular H-bonds in 2c, are observed between two Zwitterionic molecules with the distance of $\mathrm{Cl} 2 \cdots \mathrm{N} 4^{\mathrm{i}}=3.141(6) \AA(\mathrm{i}=2-\mathrm{X}, 1-\mathrm{Y},-\mathrm{Z})$, and the angle of $\mathrm{N}-\mathrm{H} \cdots \mathrm{Cl}=158.9^{\circ}$ in $R_{2}^{2}(14)$ synthon.
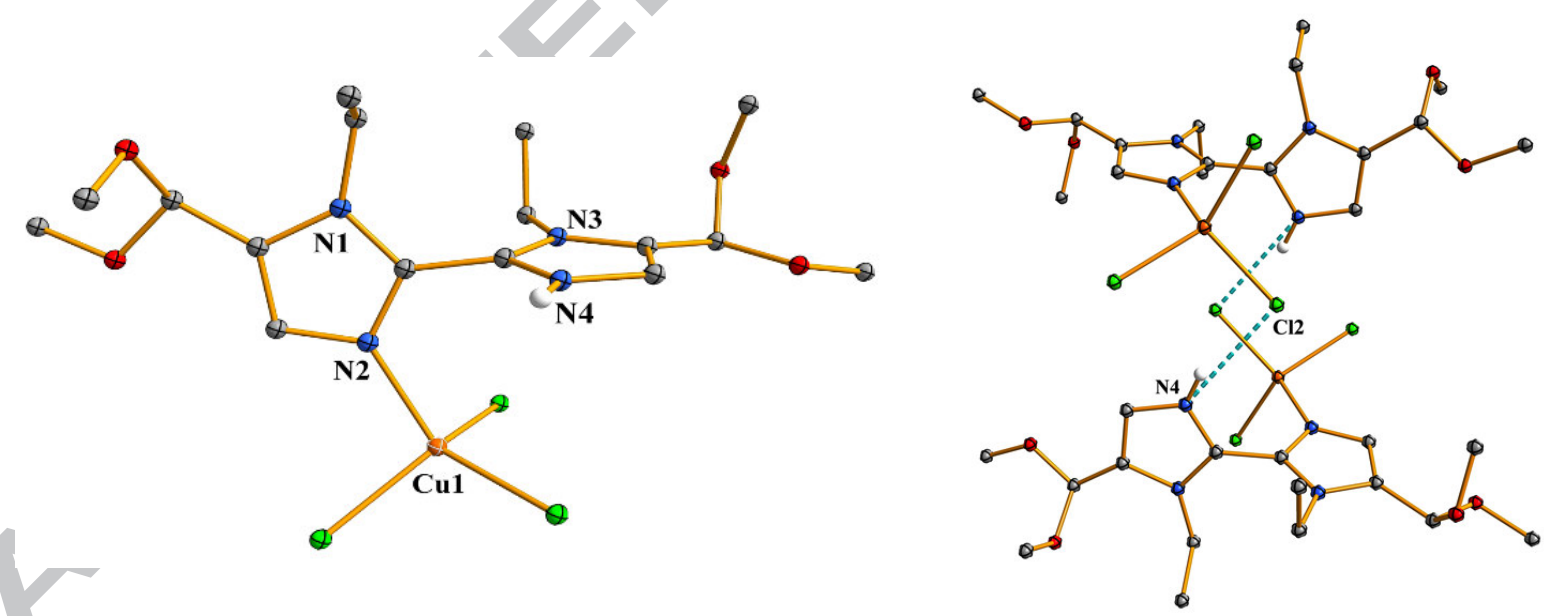

Figure 6. Molecular structure and intermolecular H-bonding in structure $2 \mathbf{c}$ in $R_{2}^{2}(14)$ synthon. C-H hydrogens are omitted for clarity (50\% probability ellipsoids).

No X-Ray quality crystals could be obtained from ([CuCl$\left.\left.\left(\mathrm{Cu}_{\mathbf{1 8}} \mathbf{H}_{31} \mathbf{N}_{4} \mathbf{O}_{4}\right)\right]\right) \mathbf{2 d}$. 
$\left[\mathrm{MCl}_{4}\right]\left[\mathrm{C}_{14} \mathrm{H}_{24} \mathbf{N}_{4} \mathrm{O}_{4}\right](\mathrm{M}=\mathrm{Zn}, 3 \mathrm{a} ; \mathrm{M}=\mathrm{Cu}, 3 \mathrm{~b})$. The ion pairs of $3 \mathrm{a}$ and $3 \mathrm{~b}$ consist of anionic metal compounds $\left(\left[\mathrm{CuCl}_{4}\right]^{2-}\right.$ and $\left.\left[\mathrm{ZnCl}_{4}\right]^{2-}\right)$ and fully protonated cationic $\left[\mathrm{C}_{14} \mathrm{H}_{24} \mathrm{~N}_{4} \mathrm{O}_{4}\right]^{2+}$. In $3 \mathrm{a}$ and $3 \mathrm{~b}$, intermolecular H-bonding was seen between cation and anionic part of the compound $\left(\mathrm{R}^{2}{ }_{2}(9)\right.$ synthon). The distance between $\mathrm{Cl} 2-\mathrm{N} 1^{\mathrm{i}}$ in $\mathbf{3 a}$ is $3.172(2) \AA$ ( $\mathrm{i}=1-\mathrm{X},+\mathrm{Y}, 3 / 2-\mathrm{Z}$ ) and the corresponding distance $\mathrm{Cl1}-\mathrm{N} 2^{\mathrm{ii}}$ in 3b 3.218(3) $\AA$ (ii= $-\mathrm{X},+\mathrm{Y}, 3 / 2-\mathrm{Z}$ ). In both structures, the imidazole rings of the cations are again not coplanar. The angles between the planes of imidazole rings are $69.3^{\circ}$ and $56.9^{\circ}$ for $\mathbf{3 a}$ and $\mathbf{3 b}$ respectively.
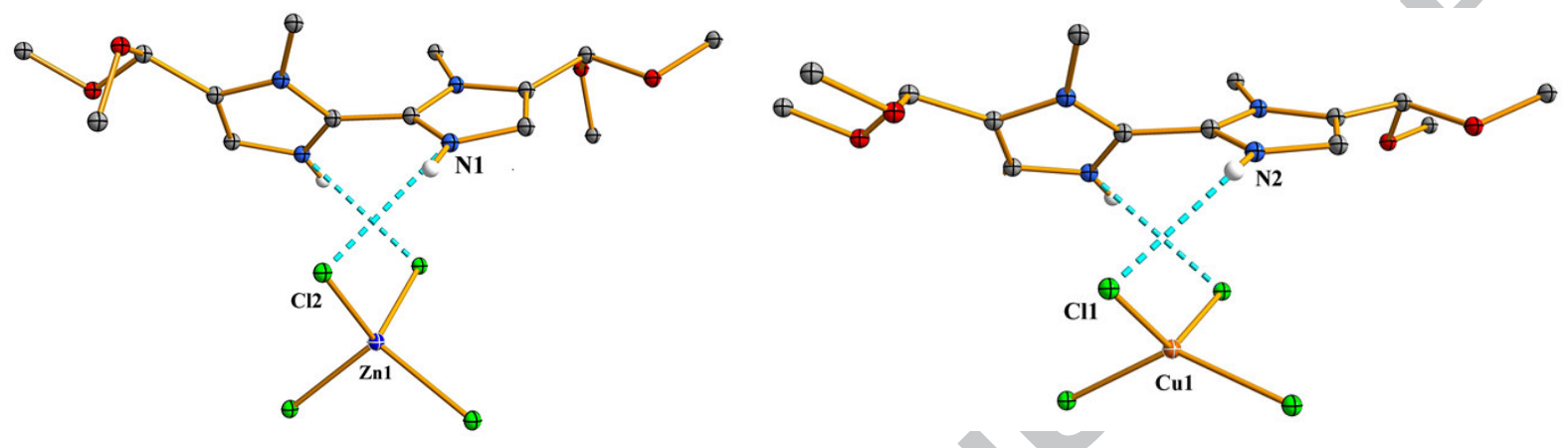

Figure 7. Molecular structure and H-bonding of $\mathbf{3 a}(\mathrm{Zn}$, right) and $\mathbf{3 b}(\mathrm{Cu}$, left). C-H hydrogens are omitted for clarity. Thermal ellipsoids are drawn at the $50 \%$ probability level. The distance of $\mathrm{Cl} 2 \cdots \mathrm{N} 1^{\mathrm{i}}$ in $\mathbf{3 a}$ is $3.172(2) \AA(\mathrm{i}=1-\mathrm{X},+\mathrm{Y}, 3 / 2-\mathrm{Z})$ and in $\mathbf{3 b}$ is $3.218(3) \AA\left(\mathrm{Cl} 1 \cdots \mathrm{N} 22^{\mathrm{i}} ; \mathrm{i}=-\mathrm{X},+\mathrm{Y}, 3 / 2-\mathrm{Z}\right)$.

\section{Conclusions}

A series of ring-substituted biimidazoles (Df-R biim; R=Me, Et or Pr) were used for the synthesis of binuclear $\mathrm{Zn}$ (II) and mononuclear $\mathrm{Cu}$ (II) compounds. Compound formation was found to depend strongly on the $\mathrm{pH}$ of the reaction medium. In neutral reaction conditions the biimidazole ligands were bidentate and acting as bridging ligands in binuclear $\mathrm{Zn}$ (II) compounds or chelating ligands in mononuclear $\mathrm{Cu}(\mathrm{II})$ compound. Lowering the $\mathrm{pH}$ to 3-4 led to partial or full protonation of the two $\mathrm{N}$ sites of the ligand. With fully protonated ligands only ion pairs $(\mathbf{3 a}, \mathbf{b})$ were obtained while reactions with partially protonated biimidazoles gave Zwitterionic compounds (2a-d). In addition to $\mathrm{pH}$, the formation of the Zwitterionic products was found to be dependent on the ring and $N$-substituents of the biimidazoles. Both of these substituents were needed for Zwitterion formation. In acidic media, the aldehyde substituent on the ring was involved in acetal formation and this process was a crucial step in obtaining Zwitterions. Longer alkyl $N$ substituents (ethyl or propyl) were also required for Zwitterion formation while methyl substituent favored ion pairs regardless of aldehyde substituent. In alcoholic solution the Zwitterionic compounds were decomposed to form free neutral ligand and $\mathrm{HZnCl}_{3}$ salt. 


\section{References}

1. a) J. Z. Vlahakis, R. T. Kinobe, R. J. Bowers, J. F. Brien, K. Nakatsu, W. A. Szarek, J. Med. Chem. 49 (2006) 4473. b) F. Yang, N. G. Nickols, B. C. Li, G. K. Marinov, J. W. Said, P. B. Dervan, PNAS. 110 (2013) 1863. c) D. Wang, J. T. Groves, PNAS. 110 (2013) 15579. d) L. Schlechte, V. Bon, R. Grunker, N. Klein, I. Senkovska, S. Kaskel, Polyhedron. 44 (2012) 179.

2. a) S. Karmakar, M. Nandi, S. Mukherjee, S. Baitalik, Inorg. Chim. Acta. 2016 (in press) b) C. Tan, S. Hu, J. Liu, L. Ji, Eur. J. Med. Chem. 46 (2011) 1555. c) M. Akkawi, A. Aljazzar, M. A. Haj, Q. Abu-Remeleh, Br. J. Pharmacol. Taxicol. 3 (2012) 65. d) P. Melloni, E. Dradi, W. Logemann, J. Med. Chem. 15 (1972) 926. e) P. Gupta, S. Hameed, R. Jain, Eur. J. Med. Chem. 39 (2004) 805. f) Y. Li, Y. Wu, J. Zhao, P. Yang, J. Inorg. Biochem. 101 (2007) 283. g) D. P. Matthew, J. R. McCarthy, J. P. Whitten, P. R. Kastner, C. L. Barney, F. N. Marshall, M. A. Ertel, T. Burkhard, P. J. Shea, T. Kariya, J. Med. Chem. 33 (1990) 317.

3. a) A. Hoang, L. Mario, J. Am. Chem. Soc. 125 (2003) 4412. b) Y. Cui, H-J. Mo, J-C. Chen, Y-L. Niu, Y-R. Zhong, K-C. Zheng, B-H. Ye, Inorg. Chem. 46 (2007) 6427. c) Q. Zeng, P. Cai, Z. Li, J. Qin, B. Z. Tang, Chem. Commun. (2008) 1094. d) Q. Zeng, C.K.W. Jim, J. W. Y. Lam, Y. Dong, Z. Li, J. Qin, B. Z. Tang, Macromol. Rapid. Commun. 30 (2009) 170. e) A. Salinas-Castillo, M. Camprubi-Robles, R. Mallavia, Chem. Commun. 46 (2010) 1263.

4. a) S. Fortin, A. L. Beauchamp, Inorg. Chem. 39 (2000) 4886. b) A. K. Ghosh, A. D. Jana, D. Ghoshal, G. Mostafa, N. Ray Chaudhuri, Cryst. Growth Des. 6 (2006) 701.

5. a) R-L. Sang, L. Xu, Eur. J. Inorg. Chem. (2006) 1260. b) J. Ying, X-L. Lin, Y-J. Liu, R. Xiao, X-L. Wang, A-X. Tian, Z. Anorg. Allg. Chem. 638 (2012) 135 .

6. a) R-L. Sang, L. Xu, Inorg. Chim. Acta. 359 (2006) 2337. b) S. Sabiah, C-S. Lee, W-S. Hwang, Ivan.J.B. Lin, Organometallics. 29 (2010) 290. c) J. L. Ferguson, C. M. Fitchett, Cryst. Growth Des. 25 (2015) 1280.

7. a) L-N. Yang, Y-X. Zhi, J-H. Hei, J. Li, F-X. Zhang, S-Y. Gao, J. Coord. Chem. 64 (2011) 2912. b) Y. Bao, H. Wang, Q. Li, B. Liu, Q. Li, W. Bai, B. Jin, R. Bai, Macromolecules. 45 (2012) 3394. c) E. Laurila, L. Oresmaa, E. Kalenius, P. Hirva, M. Haukka, Polyhedron. 52 (2013) 1231. d) Z-Y Shi, J. Peng, Y-G. Li, Z-Y. Zhang, X. Yu, K. Alimaje, X. Wang, CrystEngComm. 15 (2013) 7583.

8. a) J. S. Casas, A. Castineiras, Y. Parajo, J. Sordo, J. M. Varela, Acta Cryst. C54 (1998) 1777. b) J. S. Casas, A. Castineiras, Y. Parajo, A. Sanchez, A. Sanchez-Gonzalez, J. Sordo, Polyhedron. 24 (2005) 1196. c) G-G. Shan, H-B. Li, Z-C. Mu, D-X. Zhu, Z-M. Su, Y. Liao, J. Organomet. Chem. 702 (2012) 27.

9. a) R-L. Sang, L. Xu, Polyhedron. 25 (2006) 2167. b) R-L. Sang, L. Xu, Inorg. Chim. Acta. 359 (2006) 525. c) L. M. Gruia, F. D. Rochon, A. L. Beauchamp, Inorg. Chim. Acta. 260 (2007) 1825. d) Y-R. Zhong, M-L. Cao, H-J. Mo, B-H. Ye, Cryst. Growth. Des. 8 (2008) 2282.

10. a) Z-M. Hao, S-L. Li, X-M. Zhang, Inorg. Chem. Commun. 13 (2010) 1100. b) A-X. Tian, X-L. Lin, G-Y. Liu, R. Xiao, J. Ying, X-L. Wang, J. Coord. Chem. 66 (2013) 1340.

11. a) A: Maiboroda, G. Rheinwald, and H. Lang, Inorg. Chem. Commun. 4 (2001) 381. b) Y-H. Tan, J-S. Wu, C-S-Yang, Q-R. Liu, Y-Z. Tang, Y-R. Zhong, B-H. Ye, Inorg. Chim. Acta. 399 (2013) 45. c) S. Mardanya, S. Karmakar, D. Mondal, S. Baitalik, Inorg. Chem. 55 (2016) 3475 .

12. a) Y-P. Li, Y. Pin, Chin. J. Chem. 28 (2010) 759. b) Y-P. Li, Y. Pin, Inorg. Chem. Commun. 14 (2011) 545. c) H-J. Jia, Z. Shi, Q-F. Yang, J-H. Yu, J-Q. Xu. Dalton. Trans. 43 (2014) 5806.

13. a) J. Martinez-Lillo, D. Armentano, G. De Munno, N. Marino, F. Lloret, M. Julve, J. Faus, CrystEngComm. 10 (2008) 1284. b) J. Martinez-Lillo, A. H. Pedersen, J. Faus, M. Julve, E. K. Brechin, Cryst. Growth Des. 15 (2015) 2598.

14. a) P. G. Apen, P. G. Rasmussen, J. Am. Chem. Soc. 113 (1991) 6178. b) C. P. Causey, W. E. Allen, J. Org. Chem. 67 (2002) 5963.

15. a) P. G. Rasmussen, O. H. Bailey, J. C. Bayon, Inorg. Chem. 23 (1984) 338. b) P. G. Rasmussen, O. H. Bailey, J. C. Bayon, W. M. Butler, Inorg. Chem. 23 (1984) 343. c) J. G. Malecki, Polyhedron. 29 (2010) 2489.

16. E. Laurilla, R. Tatikonda, L. Oresma, P. Hirva, M. Haukka, CrystEngComm. 14 (2012) 8401.

17. J. P. Whitten, D. P. Mathews, J. R. McCarthy, J. Org. Chem. 51 (1986) 1891.

18. Agilent, CrysAlisPro, Agilent Technologies inc., 2013, Yarnton, Oxfordshire, England.

19. Otwinowski, Z.; Minor, W. Processing of X-ray Diffraction Data Collected in Oscillation Mode, Academic Press, New York, pp. 307-326, 1997. In Methods in Enzymology, Volume 276, Macromolecular Crystallography, Part A, Carter, C. W., Sweet, J., Eds.; Academic Press: New York, USA, 1997; pp 307-326.

20. L. Palatinus, G. Chapuis, J. Appl. Cryst. 40 (2007) 786.

21. G. M. Sheldrick, Acta Cryst. A64 (2008) 112.

22. G. M. Sheldrick, SADABS - Bruker AXS scaling and absorption correction -, Bruker AXS, Inc., Madison, Wisconsin, USA, 2012. 
23. Graphsets were analysed by using Mercury.

24. R. Sang, L. Xu, Inorg. Chem. 44 (2005) 3731.

25. W. J. Geary, Coord. Chem. Rev. 7 (1971) 81.

26. a) R. Atencio, K. Ramirez, J. A. Reyes, T. Gonzalez, P. Silva, Inorg. Chim. Acta. 358 (2005) 520. b) Q-H. Jin, L-L. Zhou, L-J. Xu, Y-Y. Zhang, C-L. Zhang, X-M. Lu, Polyhedron. 29 (2010) 317.

27. a) S. Fortin, A. L. Beauchamp, Inorg. Chem. 39 (2000) 4886. b) M. Felloni, P. Hubberstey, C. Wilson, M. Schroder, CrystEngComm. 6 (2004) 87. c) E. Laurilla, L. Oresmaa, M. Niskanen, P. Hirva, M. Haukka, Cryst. Growth Des. 10 (2010) 3775. 


\title{
Electronic Supporting Information
}

for

\section{Synthesis and Characterization of Zwitterionic $\mathrm{Zn}$ (II) and $\mathrm{Cu}$ (II) Coordination} compounds with Ring-substituted 2,2'-Biimidazole Derivatives

\author{
Rajendhraprasad Tatikonda, Elina Kalenius and Matti Haukka* \\ Department of Chemistry, University of Jyväskylä, P.O.Box 35, FI-40014 University of Jyväskylä, Finland \\ E-mail: matti.o.haukka@jyu.fi
}

\section{Experimental Section}

The ligand synthesis method was slightly modified from the literature procedure ${ }^{[17]}$ by increasing the reaction time to ensure the completion of reaction. The molar amounts of reagents were optimized to improve the yield and selectivity towards 2,2'-Bi-1R-imidazole $-5,5^{\prime}$-dicarboxaldehydes (Df- $\mathrm{R}_{2}$ biim). The reaction time was extended from $1 \mathrm{~h}$. to overnight and molar amounts of $\mathrm{n}-\mathrm{BuLi}$ and $\mathrm{DMF}$ were taken as 5 times to the $\mathrm{R}_{2}$ biim molar amount.

General procedure for 2,2’-Bi-1R-imidazole-5,5'-dicarboxaldehyde (Df-R $\mathbf{2}_{2}$ Biim; R= Me, Et and Pr)

Under argon gas, a mixture of N, $\mathrm{N}^{\prime}$-disustituted-2,2'-biimiazole ( $\mathrm{R}_{2}$ biim, $\left.2 \mathrm{mmol}\right), 0.93 \mathrm{~mL}$ (6 mmol) of TMEDA and $20 \mathrm{~mL}$ of dried THF was cooled to $-40^{\circ} \mathrm{C}$. To the above cooled solution, $2.5 \mathrm{M} \mathrm{n}$-BuLi in hexane (10 mmol) was added slowly with the help of syringe. After $15 \mathrm{~min}$ stirring at room temperature, a mixture of $0.76 \mathrm{~mL}(10 \mathrm{mmol}) \mathrm{of} \mathrm{DMF}$ in $1 \mathrm{~mL}$ of THF was added drop wise over a period of $10 \mathrm{~min}$. After complete addition of DMF, the reaction mixture was allowed for stirring overnight at room temperature. After the reaction time, the reaction mixture was diluted with $1 \mathrm{~N}$ $\mathrm{HCl}$, and extracted with ethyl acetate. The solvent was evaporated to get solid product. The product was recrystallized from ethanol.

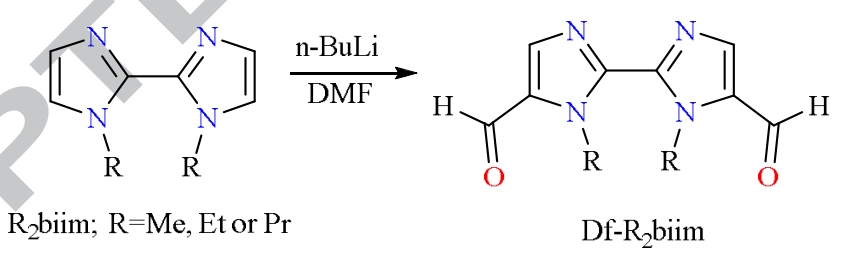

\section{2,2'-Bi-1methyl-imidazole-5,5'-dicarboxaldehyde (Df-Me2Biim)}

1a was obtained by the general procedure as a pale yellow solid with $41 \%$ of yield. mp 159.2-162.4 ${ }^{\circ} \mathrm{C}$. ${ }^{1} \mathrm{H}$ NMR $(400$ $\mathrm{MHz} \mathrm{CDC1}_{3}$ ): $\delta 4.34$ (s, 6H), 7.89 (s, 2H), 9.86 (s, 2H). ${ }^{13} \mathrm{C}$ NMR (100 MHz CDCl3): $\delta 35.17,133.00,142.64,142.87$, 179.63. HRMS $(\mathrm{m} / \mathrm{z})$ Calcd for $\mathrm{C} 10 \mathrm{H} 11 \mathrm{~N} 4 \mathrm{O} 2^{+}\left[\mathrm{M}+\mathrm{H}^{+}\right]: 219.0882$, found: 219.0873. IR (v, cm-1): 1667 (CHO).

\section{2,2'-Bi-1ethyl-imidazole-5,5'-dicarboxaldehyde (Df-Et2Biim)}

$1 \mathrm{~b}$ was obtained by the general procedure with $61 \%$ of yield. mp $146.5-149.8{ }^{\circ} \mathrm{C}$. ${ }^{1} \mathrm{H}$ NMR $\left(400 \mathrm{MHz} \mathrm{CDC} 1_{3}\right): \delta 1.41$ $(\mathrm{t}, \mathrm{J}=7.0 \mathrm{~Hz}, 6 \mathrm{H}), 4.87(\mathrm{q}, \mathrm{J}=7.0 \mathrm{~Hz}, 4 \mathrm{H}), 7.88(\mathrm{~s}, 2 \mathrm{H}), 9.82(\mathrm{~s}, 2 \mathrm{H}) .{ }^{13} \mathrm{C} \mathrm{NMR}(100 \mathrm{MHz} \mathrm{CDCl} 3): \delta 16.40,42.63$, 132.32, 142.22, 143.41, 179.15. HRMS $(\mathrm{m} / \mathrm{z})$ Calcd for C12H15N4O2+ $\left[\mathrm{M}+\mathrm{H}^{+}\right]: 247.1195$, found: $247.1185 . \mathrm{IR}(\mathrm{v}, \mathrm{cm}-$ 1): $1664(\mathrm{CHO})$. 


\section{2,2'-Bi-1propyl-imidazole-5,5'-dicarboxaldehyde (Df-Pr2Biim)}

$1 \mathrm{c}$ was obtained by the general procedure with $72 \%$ of yield. mp 126.4-128. ${ }^{\circ} \mathrm{C}^{1} \mathrm{H}$ NMR $\left(400 \mathrm{MHz} \mathrm{CDC1} 1_{3}\right): \delta 1.41$ (t, $\mathrm{J}=7.4 \mathrm{~Hz}, 6 \mathrm{H}), 1.72-1.81(\mathrm{~m}, 4 \mathrm{H}), 4.80(\mathrm{t}, \mathrm{J}=7.5 \mathrm{~Hz}, 4 \mathrm{H}), 7.87$ (s, 2H), $9.82(\mathrm{~s}, 2 \mathrm{H}) \cdot{ }^{13} \mathrm{C}$ NMR $(100 \mathrm{MHz} \mathrm{CDCl} 3): \delta$ 10.93, 24.45, 48.40, 132.52, 142.57, 143.31, 179.22. HRMS ( $\mathrm{m} / \mathrm{z}$ ) Calcd for $\mathrm{C} 14 \mathrm{H} 19 \mathrm{~N} 4 \mathrm{O} 2^{+}\left[\mathrm{M}+\mathrm{H}^{+}\right]: 275.1508$, found: 275.1506. IR ( $v, \mathrm{~cm}-1)$ : 1662 (CHO).

\section{X-ray Crystallography}

Table S1. Crystallographic Data for Compounds 1-3.

\begin{tabular}{|c|c|c|c|c|c|c|c|}
\hline & $1 b$ & $1 d$ & $2 a$ & $2 \mathbf{b}$ & $2 c$ & $3 \mathbf{a}$ & $3 \mathbf{b}$ \\
\hline CCDC No. & 1443455 & 1443456 & 1443457 & 1443458 & 1443461 & 1443462 & 1443459 \\
\hline Formula & $\begin{array}{l}\mathrm{C}_{24} \mathrm{H}_{28} \mathrm{~N}_{8} \mathrm{O}_{4} \\
\mathrm{Zn}_{2} \mathrm{Cl}_{4}\end{array}$ & $\begin{array}{l}\mathrm{C}_{10} \mathrm{H}_{10} \mathrm{~N}_{4} \mathrm{O}_{2} \\
\mathrm{CuCl}_{2}\end{array}$ & $\begin{array}{l}\mathrm{C}_{16} \mathrm{H}_{27} \mathrm{~N}_{4} \mathrm{O}_{4} \\
\mathrm{ZnCl}_{3}\end{array}$ & $\begin{array}{l}\mathrm{C}_{18} \mathrm{H}_{31} \mathrm{~N}_{4} \mathrm{O}_{4} \\
\mathrm{ZnCl}_{3}, \mathrm{CH}_{4} \mathrm{O}\end{array}$ & $\begin{array}{l}\mathrm{C}_{16} \mathrm{H}_{27} \mathrm{~N}_{4} \mathrm{O}_{4} \\
\mathrm{CuCl}_{3}\end{array}$ & $\begin{array}{l}\mathrm{C}_{14} \mathrm{H}_{24} \mathrm{~N}_{4} \mathrm{O}_{4}, \\
\mathrm{ZnCl}_{4}\end{array}$ & $\begin{array}{l}\mathrm{C}_{14} \mathrm{H}_{24} \mathrm{~N}_{4} \mathrm{O}_{4}, \\
\mathrm{CuCl}_{4}\end{array}$ \\
\hline Fw & 765.08 & 352.66 & 511.13 & 571.23 & 509.30 & 519.54 & 517.71 \\
\hline Temp (K) & 123 & 123 & 120 & 123 & 123 & 123 & 123 \\
\hline Cryst syst & Monoclinic & Monoclinic & Triclinic & Triclinic & Triclinic & Orthorhombic & Monoclinic \\
\hline Space group & $P 2_{1} / \mathrm{c}$ & $C 2 / \mathrm{c}$ & $P \overline{1}$ & $P \overline{1}$ & $P \overline{1}$ & $P b c n$ & $C 2 / \mathrm{c}$ \\
\hline a $(\AA)$ & $9.4812(2)$ & $19.8441(1)$ & $9.6893(2)$ & $8.8362(4)$ & $9.6212(18)$ & $20.2149(6)$ & $21.8044(18)$ \\
\hline $\mathrm{b}(\AA)$ & $13.1493(3)$ & $10.0122(4)$ & $11.2715(4)$ & $12.3593(9)$ & $11.287(2)$ & $8.9789(2)$ & $7.8148(5)$ \\
\hline c $(\AA)$ & $13.5024(3)$ & $6.9417(3)$ & $11.6686(4)$ & 13.1451(7) & $11.8379(19)$ & $11.5719(3)$ & $12.4029(8)$ \\
\hline$\alpha\left({ }^{\circ}\right)$ & 90 & 90.00 & $68.9230(1)$ & $66.645(6)$ & $67.948(16)$ & 90.00 & 90.00 \\
\hline$\beta\left(^{\circ}\right)$ & $108.213(2)$ & $112.746(6)$ & $69.619(2)$ & $86.297(4)$ & $68.641(16)$ & 90.00 & $106.338(8)$ \\
\hline$\gamma\left({ }^{\circ}\right)$ & 90 & 90.00 & $81.483(2)$ & $85.264(5)$ & $77.051(15)$ & 90.00 & 90.00 \\
\hline $\mathrm{V}\left(\AA^{3}\right)$ & 1599.02(6) & $1271.94(11)$ & $1114.28(6)$ & $1312.66(13)$ & $1104.0(4)$ & $2100.41(1)$ & 2028.1(3) \\
\hline $\mathrm{Z}$ & 2 & & 2 & 2 & 2 & 4 & 4 \\
\hline$d_{\text {calc }}\left(\mathrm{g} / \mathrm{cm}^{3}\right)$ & 1.589 & 1.842 & 1.523 & 1.445 & 1.532 & 1.643 & 1.696 \\
\hline$\mu\left(\mathrm{mm}^{-1}\right)$ & 5.293 & 6.339 & 1.490 & 1.276 & 4.992 & 6.557 & 6.629 \\
\hline Ref. collected & 6291 & 2076 & 15345 & 10339 & 6759 & 5298 & 3613 \\
\hline Ind. reflections & 3011 & 1219 & 5713 & 5435 & 4203 & 2148 & 1912 \\
\hline $\mathrm{F}(000)$ & 776 & 708 & 528 & 596 & 526 & 1064 & 1060 \\
\hline GOF & 1.079 & 1.059 & 1.107 & 1.033 & 0.960 & 1.062 & 1.060 \\
\hline $\mathrm{R}_{\text {int }} \bigcirc$ & 0.0215 & 0.0377 & 0.0322 & 0.0149 & 0.0716 & 0.0215 & 0.0558 \\
\hline $\mathrm{R} 1^{\mathrm{a}}(I \geq 2 \sigma)$ & 0.0320 & 0.0328 & 0.0366 & 0.0259 & 0.0578 & 0.0315 & 0.0467 \\
\hline$w R 2^{\mathrm{b}}(I \geq 2 \sigma)$ & 0.1170 & 0.0703 & 0.0695 & 0.0613 & 0.1187 & 0.0850 & 0.1210 \\
\hline
\end{tabular}

${ }^{a} R 1=\Sigma\left\|F_{\mathrm{o}}|-| F_{\mathrm{c}}\right\| / \Sigma\left|F_{\mathrm{o}}\right|{ }^{b} \mathrm{wR} 2=\left[\Sigma\left[w\left(F_{\mathrm{o}}{ }^{2}-F_{\mathrm{c}}{ }^{2}{ }^{2}\right] / \Sigma\left[w\left(F_{\mathrm{o}}{ }^{2}\right)^{2}\right]\right]^{1 / 2}\right.$. 


\section{ACCEPTED MANUSCRIPT}

Table S2. Selected bond lengths $(\stackrel{\mathrm{A}}{)})$ and angles $\left({ }^{\circ}\right)$ for Compounds 1-3.

\begin{tabular}{|c|c|c|c|c|c|c|c|}
\hline \multicolumn{8}{|c|}{ Compound 1b } \\
\hline $\mathrm{Zn} 1-\mathrm{Cl} 1$ & $2.2193(6)$ & $\mathrm{Zn} 1-\mathrm{Cl} 2$ & $2.2072(5)$ & $\mathrm{Zn} 1-\mathrm{N} 2$ & $2.0637(2)$ & $\mathrm{Zn} 1-\mathrm{N} 4$ & $2.0535(2)$ \\
\hline $\mathrm{Cl} 1-\mathrm{Zn} 1-\mathrm{Cl} 2$ & $123.87(3)$ & N4-Zn1-Cl1 & $104.22(5)$ & $\mathrm{N} 4-\mathrm{Zn} 1-\mathrm{Cl} 2$ & $111.10(5)$ & $\mathrm{N} 2-\mathrm{Zn} 1-\mathrm{Cl} 1$ & $102.39(5)$ \\
\hline $\mathrm{N} 2-\mathrm{Zn} 1-\mathrm{Cl} 2$ & $110.83(5)$ & $\mathrm{N} 4-\mathrm{Zn} 1-\mathrm{N} 2$ & $102.04(7)$ & & & & \\
\hline \multicolumn{8}{|c|}{ Compound 1d } \\
\hline $\mathrm{Cu} 1-\mathrm{Cl} 1$ & $2.2261(6)$ & $\mathrm{Cu} 1-\mathrm{N} 2$ & $1.988(2)$ & & & & \\
\hline $\mathrm{C} 11^{1}-\mathrm{Cu} 1-\mathrm{Cl} 1$ & $96.45(3)$ & N2-Cu1-Cl11 & $169.78(6)$ & N2-Cu1-Cl1 & $92.52(6)$ & $\mathrm{N} 2-\mathrm{Cu} 1-\mathrm{N} 2^{1}$ & $79.01(12)$ \\
\hline \multicolumn{8}{|c|}{ Compound 2a } \\
\hline $\mathrm{Zn} 1-\mathrm{Cl} 1$ & $2.2422(6)$ & $\mathrm{Zn} 1-\mathrm{Cl} 2$ & $2.2603(6)$ & $\mathrm{Zn} 1-\mathrm{Cl} 3$ & $2.2705(6)$ & $\mathrm{Zn} 1-\mathrm{N} 2$ & $2.0541(17)$ \\
\hline $\mathrm{Cl} 1-\mathrm{Zn} 1-\mathrm{Cl} 2$ & $119.33(2)$ & $\mathrm{Cl} 1-\mathrm{Zn} 1-\mathrm{Cl} 3$ & $112.99(2)$ & $\mathrm{Cl} 2-\mathrm{Zn} 1-\mathrm{Cl} 3$ & $107.06(2)$ & N2-Zn1- & 103.94(5) \\
\hline $\mathrm{N} 2-\mathrm{Zn} 1-\mathrm{Cl} 2$ & $102.31(5)$ & $\mathrm{N} 2-\mathrm{Zn} 1-\mathrm{Cl} 3$ & $110.50(5)$ & & & & \\
\hline \multicolumn{8}{|c|}{ Compound 2b } \\
\hline $\mathrm{Zn} 1-\mathrm{Cl} 1$ & $2.2494(5)$ & $\mathrm{Zn} 1-\mathrm{Cl} 2$ & $2.2664(5)$ & $\mathrm{Zn} 1-\mathrm{Cl} 3$ & $2.2299(5)$ & $\mathrm{Zn} 1-\mathrm{N} 2$ & $2.0519(14)$ \\
\hline $\mathrm{Cl} 1-\mathrm{Zn} 1-\mathrm{Cl} 2$ & $106.641(2)$ & $\mathrm{Cl} 1-\mathrm{Zn} 1-\mathrm{Cl} 3$ & $119.22(2)$ & $\mathrm{Cl} 2-\mathrm{Zn} 1-\mathrm{Cl} 3$ & $110.153(2)$ & $\mathrm{N} 2-\mathrm{Zn} 1-\mathrm{Cl} 1$ & $108.46(4)$ \\
\hline $\mathrm{N} 2-\mathrm{Zn} 1-\mathrm{Cl} 2$ & $108.12(4)$ & $\mathrm{N} 2-\mathrm{Zn} 1-\mathrm{Cl} 3$ & $103.82(4)$ & & & & \\
\hline \multicolumn{8}{|c|}{ Compound 2c } \\
\hline $\mathrm{Cu} 1-\mathrm{Cl} 1$ & $2.2392(2)$ & $\mathrm{Cu} 1-\mathrm{Cl} 2$ & $2.2585(2)$ & $\mathrm{Cu} 1-\mathrm{Cl} 3$ & $2.2370(2)$ & $\mathrm{Cu} 1-\mathrm{N} 2$ & $2.002(4)$ \\
\hline $\mathrm{Cl} 1-\mathrm{Cu} 1-\mathrm{Cl} 2$ & $100.56(6)$ & $\mathrm{Cl} 1-\mathrm{Cu} 1-\mathrm{Cl} 3$ & $133.58(7)$ & $\mathrm{Cl} 2-\mathrm{Cu} 1-\mathrm{Cl} 3$ & $102.89(6)$ & N2-Cu1-Cl1 & $97.36(13)$ \\
\hline $\mathrm{N} 2-\mathrm{Cu} 1-\mathrm{Cl} 2$ & $130.63(14)$ & $\mathrm{N} 2-\mathrm{Cu} 1-\mathrm{Cl} 3$ & $96.89(13)$ & & & & \\
\hline \multicolumn{8}{|c|}{ Compound 3a $\square$} \\
\hline $\mathrm{Zn} 1-\mathrm{Cl} 1$ & $2.2721(5)$ & $\mathrm{Zn} 1-\mathrm{Cl} 2$ & $2.2851(4)$ & & & & \\
\hline $\mathrm{Cl} 11^{1}-\mathrm{Zn} 1-\mathrm{Cl} 1$ & $110.86(3)$ & $\mathrm{Cl} 1^{1}-\mathrm{Zn} 1-\mathrm{Cl} 2$ & $109.817(17)$ & $\mathrm{Cl} 1-\mathrm{Zn} 1-\mathrm{Cl} 2$ & $107.900(16)$ & $\mathrm{Cl} 1^{1}-\mathrm{Zn} 1-\mathrm{Cl} 2^{1}$ & $107.898(16)$ \\
\hline $\mathrm{Cl} 1-\mathrm{Zn} 1-\mathrm{Cl} 2^{1}$ & $109.817(16)$ & $\mathrm{Cl} 2-\mathrm{Zn} 1-\mathrm{Cl} 2^{1}$ & $110.817(16)$ & 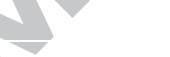 & & & \\
\hline \multicolumn{8}{|c|}{ Compound 3b } \\
\hline $\mathrm{Cu} 1-\mathrm{Cl} 1$ & $2.2562(8)$ & $\mathrm{Cu} 1-\mathrm{Cl} 2$ & $2.2447(8)$ & & & & \\
\hline $\mathrm{Cl} 1^{1}-\mathrm{Cu} 1-\mathrm{Cl} 1$ & $129.59(5)$ & $\mathrm{Cl} 1^{1}-\mathrm{Cu} 1-\mathrm{Cl} 2$ & $98.85(3)$ & $\mathrm{Cl} 1-\mathrm{Cu} 1-\mathrm{Cl} 2$ & $100.28(3)$ & $\mathrm{Cl} 1^{1}-\mathrm{Cu} 1-\mathrm{Cl} 2^{1}$ & $100.28(3)$ \\
\hline $\mathrm{Cl} 1-\mathrm{Cu} 1-\mathrm{Cl} 2^{1}$ & $98.85(3)$ & $\mathrm{Cl} 2-\mathrm{Cu} 1-\mathrm{Cl}^{1}$ & $134.08(5)$ & & & & \\
\hline
\end{tabular}




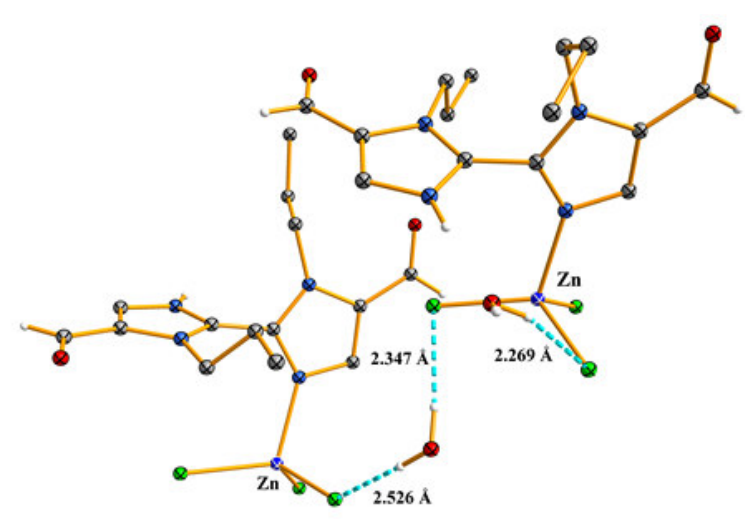

$\underline{2 b 1}$

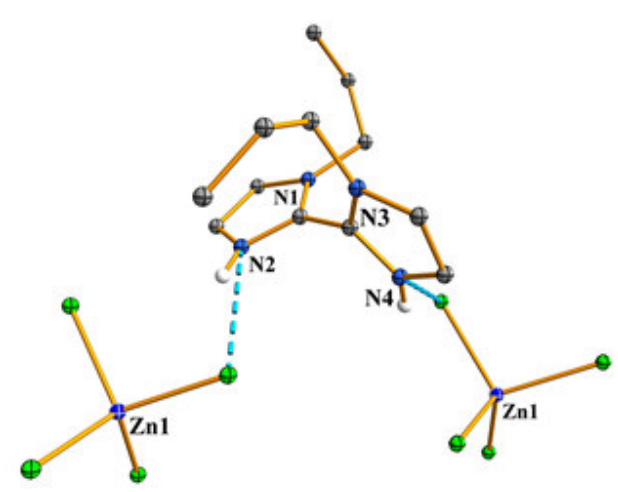

$\underline{4 b}$

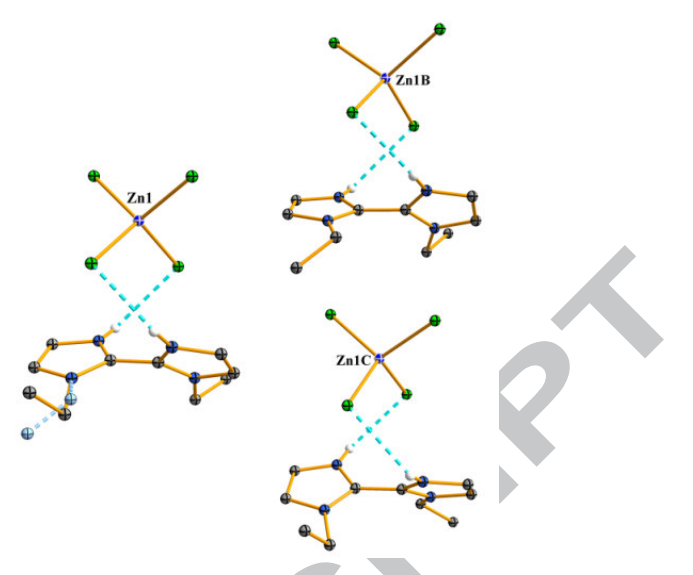

$\underline{4 a}$

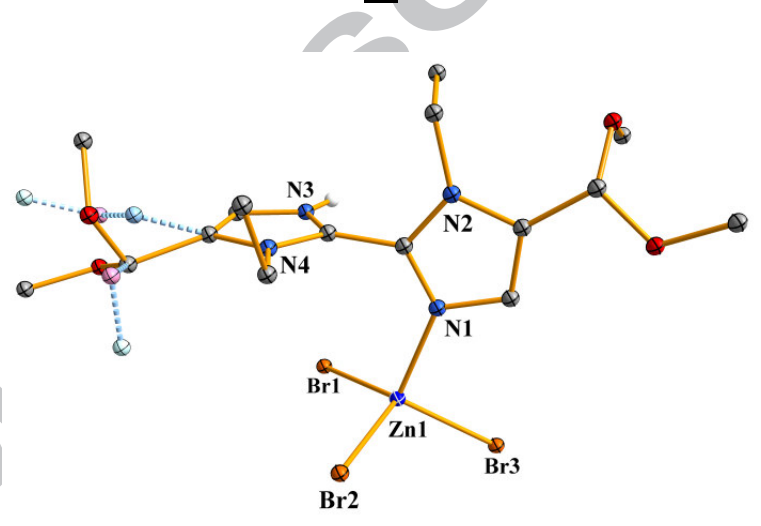

$\underline{5}$

Figure S1. Molecular structures of 2b1, 4ab and 5. C-H hydrogens are omitted for clarity. Thermal ellipsoids are drawn at the 50\% probability level.

In crystal structure (4a) one of the ethyl substituent (C9C, C10D/C9D, C10D) was disordered over two sites with occupancy ratio of $0.48 / 0.52$. The carbon atoms of the disordered groups were restrained with effective standard deviation 0.01 so that their $U_{i j}$ components approximate to isotropic behavior. The highest peak is located $1.04 \AA$ from atom $\mathrm{C} 10$ and the deepest hole is located $0.64 \AA$ from atom $\mathrm{Zn} 1 \mathrm{~B}$.

In crystal structure (5) some of the alkoxy groups (C13-C15B) were disordered over two sites with occupancy ratio of 0.57/0.43. The $\mathrm{Br} 2$ atom was also sligthlty disordered but no disorder model was used in the final structure refinement. The highest peak is located $0.74 \AA$ from atom $\mathrm{Br} 2$ and the deepest hole is located 0.80 Afrom atom $\mathrm{Br} 2$. 
Table S3. Crystallographic data for Compounds 2b1, 4ab and 5.

\begin{tabular}{|c|c|c|c|c|}
\hline & $2 b 1$ & $4 a$ & $4 b$ & 5 \\
\hline CCDC No & 1443460 & 1443464 & 1443463 & 1443465 \\
\hline Formula & $\mathrm{C}_{14} \mathrm{H}_{21} \mathrm{Cl}_{3} \mathrm{~N}_{4} \mathrm{O}_{3} \mathrm{Zn}$ & $\mathrm{C}_{10} \mathrm{H}_{10} \mathrm{~N}_{4}, \mathrm{ZnCl}_{4}$ & $\mathrm{C}_{12} \mathrm{H}_{20} \mathrm{~N}_{4}, \mathrm{ZnCl}_{4}$ & $\mathrm{C}_{16} \mathrm{H}_{27} \mathrm{Br}_{3} \mathrm{~N}_{4} \mathrm{O}_{4} \mathrm{Zn}$ \\
\hline M.Wt & 465.07 & 399.44 & 427.49 & 644.51 \\
\hline Temp (K) & 123 & 123 & 120 & 123 \\
\hline Crystal size/mm3 & $0.246 \times 0.105 \times 0.089$ & $0.080 \times 0.060 \times 0.020$ & $0.260 \times 0.211 \times 0.121$ & $0.120 \times 0.043 \times 0.025$ \\
\hline Crystal system & Monoclinic & Monoclinic & Monoclinic & Triclinic \\
\hline Space group & $P 2_{1} / \mathrm{n}$ & $P 2_{1} / \mathrm{c}$ & $P 2_{1}$ & $P \overline{1}$ \\
\hline 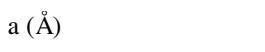 & $14.32177(16)$ & $15.2092(3)$ & $7.89382(12)$ & $9.7953(5)$ \\
\hline $\mathrm{b}(\stackrel{\mathrm{A}}{)})$ & $16.70257(18)$ & $25.9668(8)$ & $7.77587(11)$ & $11.4088(6)$ \\
\hline c $(\AA)$ & $17.48443(19)$ & $12.0487(4)$ & $14.6157(2)$ & $11.9915(7)$ \\
\hline$\alpha\left(^{\circ}\right)$ & 90 & 90 & 90 & $67.561(5)$ \\
\hline$\beta\left(^{\circ}\right)$ & $104.3992(12)$ & $95.734(2)$ & $96.2789(14)$ & $68.652(5)$ \\
\hline$\gamma\left({ }^{\circ}\right)$ & 90 & 90 & 90 & $82.433(4)$ \\
\hline $\operatorname{Vol}\left(\AA^{3}\right)$ & $4051.07(8)$ & $4734.6(2)$ & $891.75(2)$ & $1153.60(12)$ \\
\hline $\mathrm{Z}$ & 8 & 12 & 2 & 2 \\
\hline $\mathrm{d}_{\text {calc }}\left(\mathrm{g} / \mathrm{cm}^{-3}\right)$ & 1.525 & 1.681 & 1.592 & 1.855 \\
\hline$\mu\left(\mathrm{mm}^{-1}\right)$ & 1.628 & 8.326 & 1.974 & 7.811 \\
\hline $\mathrm{F}(000)$ & 1904 & 2424 & 436 & 636 \\
\hline reflns collected & 28961 & 20774 & 3102 & 8400 \\
\hline Independent reflections & 8779 & 9732 & 1631 & 4682 \\
\hline GOF & 1.053 & 1.082 & 1.045 & 1.042 \\
\hline Rint & 0.0318 & 0.0242 & 0.0206 & 0.0386 \\
\hline $\mathrm{R} 1 \mathrm{a}(\mathrm{I} \geq 2 \sigma)$ & 0.0389 & 0.0455 & 0.0214 & 0.0517 \\
\hline$w R 2 b(I \geq 2 \sigma)$ & 0.0958 & 0.1171 & 0.0488 & 0.1394 \\
\hline
\end{tabular}

${ }^{a} R 1=\Sigma\left\|F_{\mathrm{o}}|-| F_{\mathrm{c}}\right\| / \Sigma\left|F_{\mathrm{o}}\right|{ }^{b} \mathrm{wR} 2=\left[\Sigma\left[w\left(F_{\mathrm{o}}{ }^{2}-F_{\mathrm{c}}{ }^{2}\right)^{2}\right] / \Sigma\left[w\left(F_{\mathrm{o}}{ }^{2}\right)^{2}\right]\right]^{1 / 2}$.

\section{Solution studies of $Z$ witterionic coordination compounds (2a-b)}

\subsection{Molar conductivity.}

Molar conductivity of Zwitterionic coordination compounds (2a-b) in methanol solution was performed by using handylab LF11instrument manufactured by Scott.

Table S4. Molar conductivity of Zwitterionic coordination compounds (2a-d) in methanol solution

\begin{tabular}{|l|l|l|l|l|}
\hline & Conc. $(\mathrm{mmol})$ & $\mathrm{K}(\mu \mathrm{s} / \mathrm{cm})$ & $\mathrm{K}(\mathrm{s} / \mathrm{cm})$ & $\begin{array}{l}\text { Molar conductivity } \\
\Delta \mathrm{m}\left(\mathrm{Scm}^{2} \mathrm{~mol}^{-1}\right)\end{array}$ \\
\hline \multirow{2}{*}{$\mathbf{2 a}$} & 1 & 93.3 & 0.0000933 & 0.0933 \\
\hline & 0.5 & 52.4 & 0.0000524 & 0.0524 \\
\hline \multirow{2}{*}{$2 \mathbf{b}$} & & & & \\
\hline & 1 & 92.4 & 0.0000924 & 0.0924 \\
\cline { 2 - 5 } & 0.5 & 52.7 & 0.000052 .7 & 0.0527 \\
\hline KCl (Ref) & 0.5 & & & 0.0527 \\
\hline
\end{tabular}




\subsection{Mass Spectrometry}

\section{Experimental}

Mass spectrometry experiments were performed with ABSciex QSTAR Elite ESI-Q-TOF mass spectrometer equipped with an API 200 TurbolonSpray ESI source from AB Sciex (former MDS Sciex) in Concord, Ontario (Canada). The parameters were optimized to get maximum abundance of the ions under study. Both positive and negative polarization

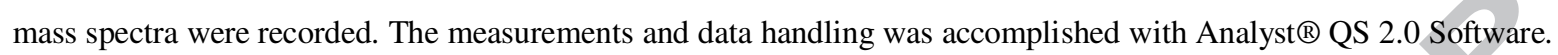

For ESI-MS measurements, solid 2a and $\mathbf{2 b}$ were dissolved in $\mathrm{MeOH}$ to obtain a stock solution of $1 \mathrm{mg} \mathrm{mL}^{-1}$. The stock solution was diluted in $\mathrm{MeOH}$ to obtain final samples $(20 \mu \mathrm{M})$. The samples were injected into the electrospray ionization (ESI) source with a flow rate of $5 \mu \mathrm{L} \mathrm{min}{ }^{-1}$. Mass spectra were externally calibrated by ESI Tuning mix (Agilent Technologies). The compositions of the ions were verified by comparing experimental and theoretical mass values as well as isotopic distributions.

\section{Results}

ESI-MS analyses for $\mathbf{2 a}$ and $\mathbf{2 b}$ were performed on positive and negative polarizations and they produced very similar spectra in methanol. In positive polarization spectra ions corresponding to $\left[2-\mathrm{ZnCl}_{3}\right]^{+}$were observed as base peaks (see Fig. XX and Table $\mathrm{X}$ for interpretation and mass accuracies). In addition peaks for sodium adduct $\left[2-\mathrm{ZnHCl}_{3}+\mathrm{Na}\right]^{+}$, methanol elimination product $\left[2-\mathrm{ZnCl}_{3}-\mathrm{MeOH}\right]^{+}$and dimeric ion $\left[(2)_{2}+\mathrm{Zn}\right]^{2+}$ were detected. On negative polarization from both compounds $\left[\mathrm{ZnCl}_{3}\right]^{-}$at $\mathrm{m} / \mathrm{z} 168$ was observed as the most abundant peak.

\begin{tabular}{|c|c|c|c|c|}
\hline Ion & Composition & $m / z_{\text {exp }}$ & $m / z_{\text {theor }}$ & $\Delta(\mathbf{m} / \mathbf{z})$ \\
\hline$\left[\mathbf{2} \mathbf{a}-\mathrm{ZnCl}_{3}\right]^{+}$ & $\mathrm{H}_{27} \mathrm{I}$ & 339.1892 & 339.2027 & 0.013 \\
\hline$\left[\mathbf{2 a}-\mathrm{ZnCl}_{3}-\mathrm{MeOH}\right]^{+}$ & $\mathrm{C}_{15} \mathrm{H}_{23} \mathrm{~N}_{4} \mathrm{O}_{3}$ & 307.1743 & 307.1765 & 0.002 \\
\hline$\left[\mathbf{2} \mathbf{a}-\mathrm{ZnHCl}_{3}\right.$ & $\mathrm{C}_{16} \mathrm{H}_{26} \mathrm{~N}_{4} \mathrm{O}_{4} \mathrm{Na}$ & 361.1805 & 361.1846 & 0.004 \\
\hline$\left[(\mathbf{2 a})_{2}+2\right.$ & $\mathrm{C}_{32} \mathrm{H}_{52} \mathrm{~N}_{8} \mathrm{O}_{8} \mathrm{Zn}$ & 370.1675 & 370.1594 & -0.008 \\
\hline$\left[\mathrm{ZnCl}_{3}\right]^{-}$ & $\mathrm{Cl}_{3} \mathrm{Zn}$ & 168.7905 & 168.8363 & 0.046 \\
\hline$\left[2 \mathbf{b}-\mathrm{ZnCl}_{3}\right]^{+}$ & $\mathrm{C}_{18} \mathrm{H}_{31} \mathrm{~N}_{4} \mathrm{O}_{4}$ & 367.2305 & 367.234 & 0.003 \\
\hline$\left[\mathbf{2 b}-\mathrm{ZnCl}_{3}-\mathrm{MeOH}\right]^{+}$ & $\mathrm{C}_{17} \mathrm{H}_{27} \mathrm{~N}_{4} \mathrm{O}_{3}$ & 335.2088 & 335.2078 & -0.001 \\
\hline$\left[\mathbf{2 b}-\mathrm{ZnHCl}_{3}+\mathrm{Na}\right]^{+}$ & $\mathrm{C}_{18} \mathrm{H}_{30} \mathrm{~N}_{4} \mathrm{O}_{4} \mathrm{Na}$ & 389.2132 & 389.2159 & 0.003 \\
\hline$\left[(\mathbf{2 b})_{2}+\mathrm{Zn}\right]^{2+}$ & $\mathrm{C}_{18} \mathrm{H}_{31} \mathrm{~N}_{4} \mathrm{O}_{4}$ & 398.1992 & 398.1907 & -0.009 \\
\hline
\end{tabular}



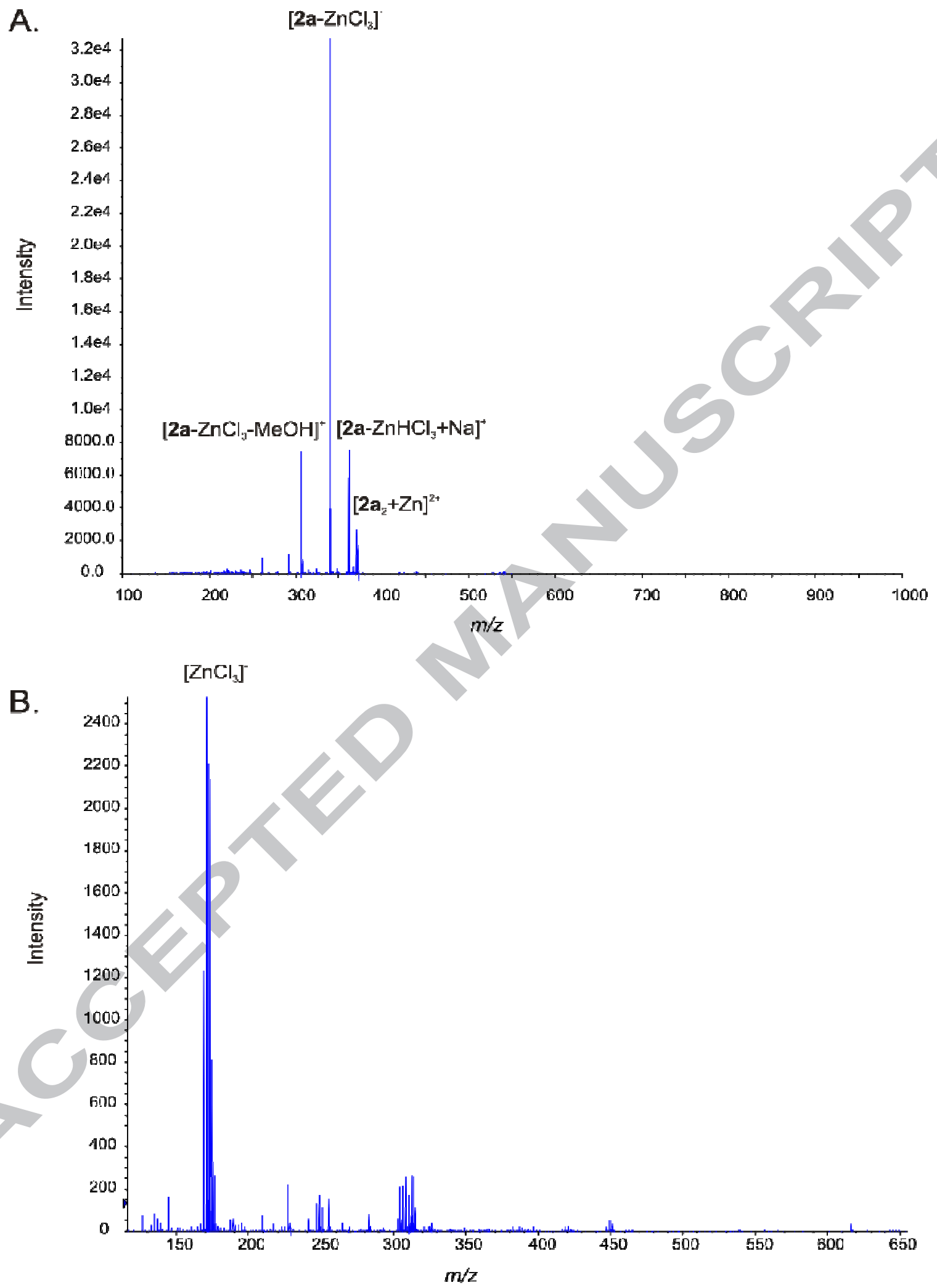

Figure S2. ESI-MS spectra from 2a $20 \mu \mathrm{M}$ in $\mathrm{MeOH}$; a) positive and b) negative polarization. 


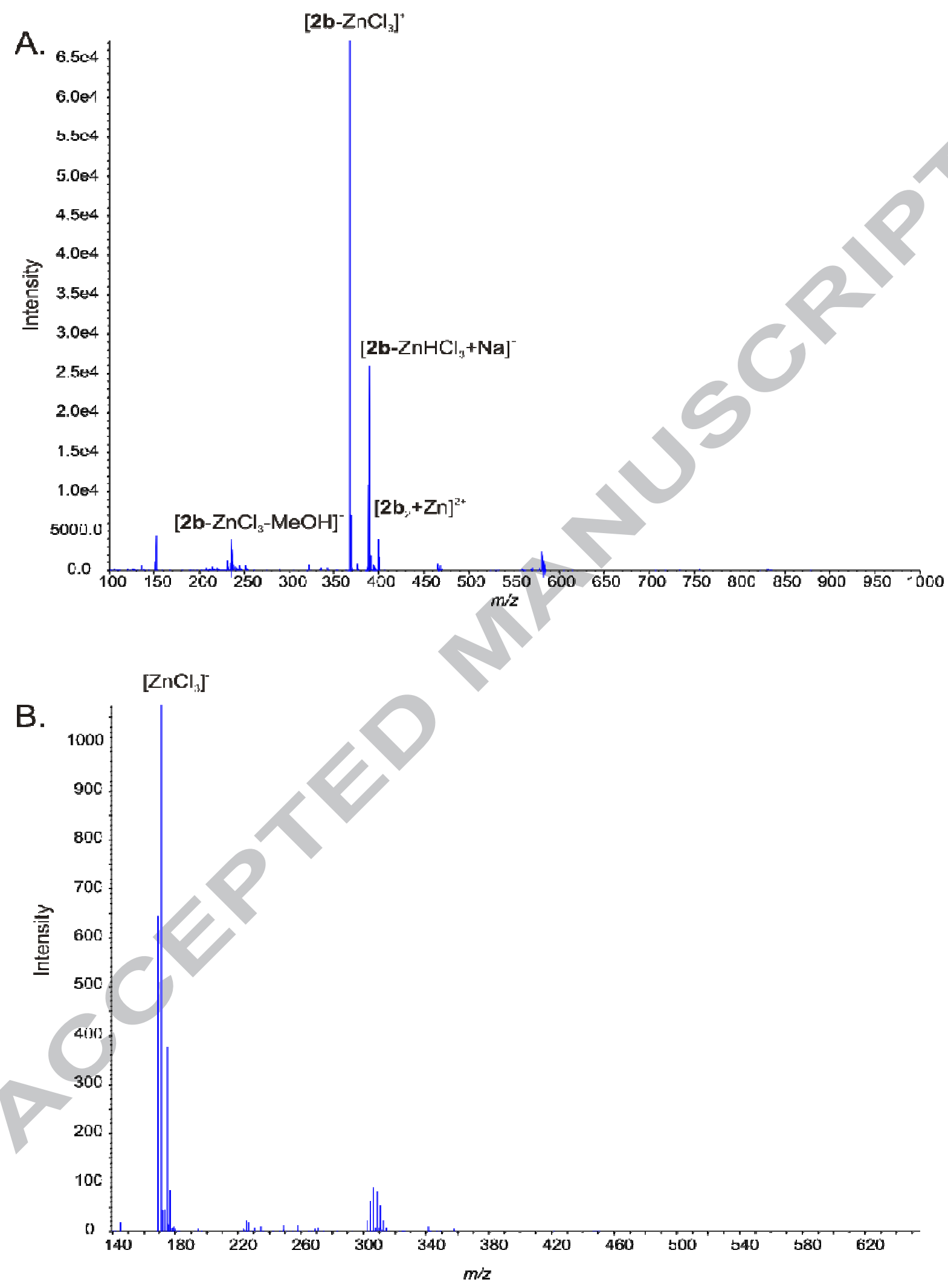

Figure S3. ESI-MS spectra from $\mathbf{2 b} 20 \mu \mathrm{M}$ in $\mathrm{MeOH}$; a) positive and b) negative polarization. 
$\stackrel{\infty}{i}$

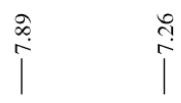<smiles>Cn1c(C=O)cnc1-c1ncc(C=O)n1C</smiles>
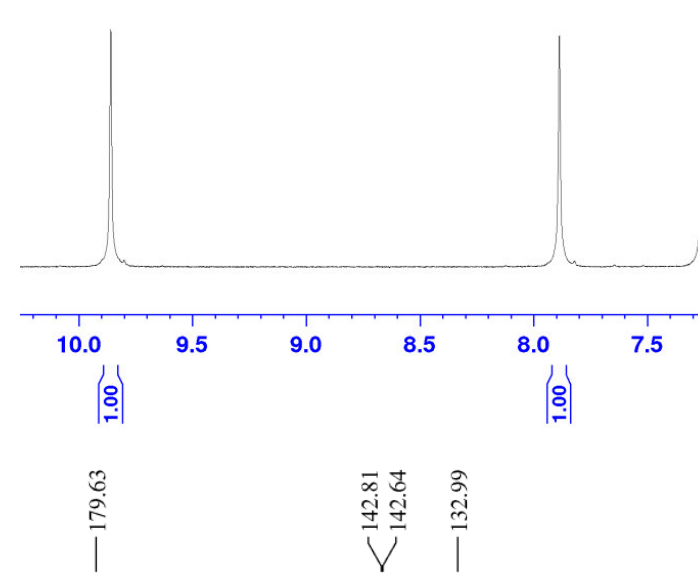

|
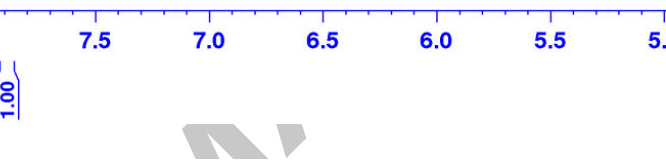

|ᄒ़्

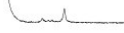

ปั

ตें

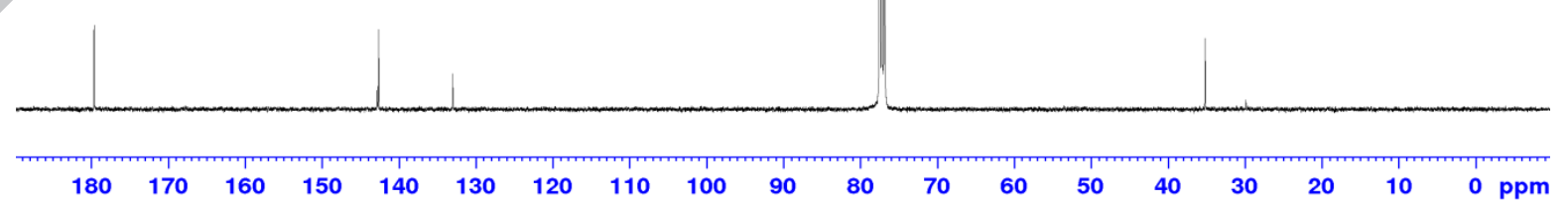


Figure S4. ${ }^{1} \mathrm{H}$ NMR (top) and ${ }^{13} \mathrm{C}$ NMR (bottom) spectra of Df-Me 2 biim in $\mathrm{CDCl}_{3}$.
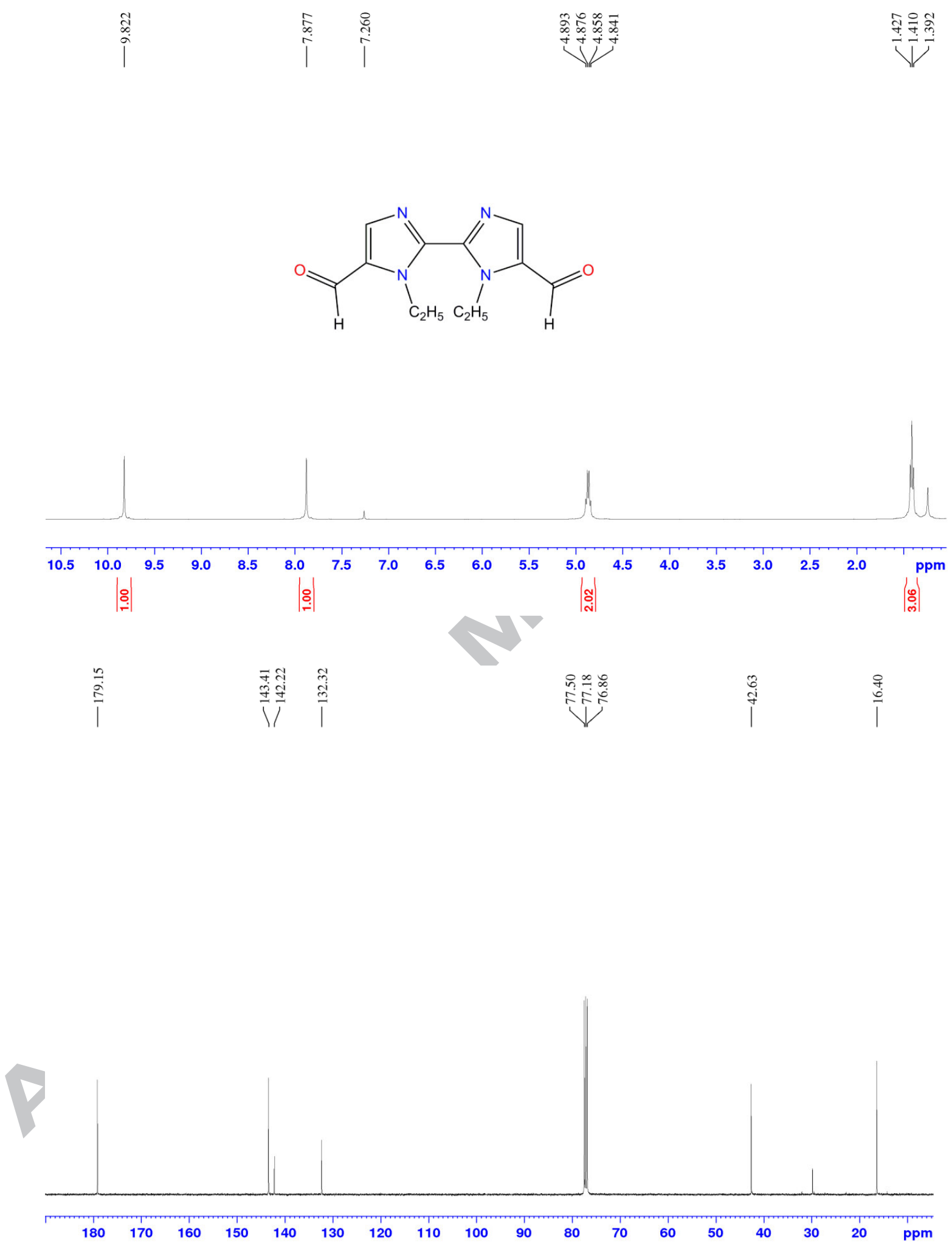

Figure S5. ${ }^{1} \mathrm{H}$ NMR (top) and ${ }^{13} \mathrm{C}$ NMR (bottom) spectra of Df-Et 2 biim in $\mathrm{CDCl}_{3}$. 

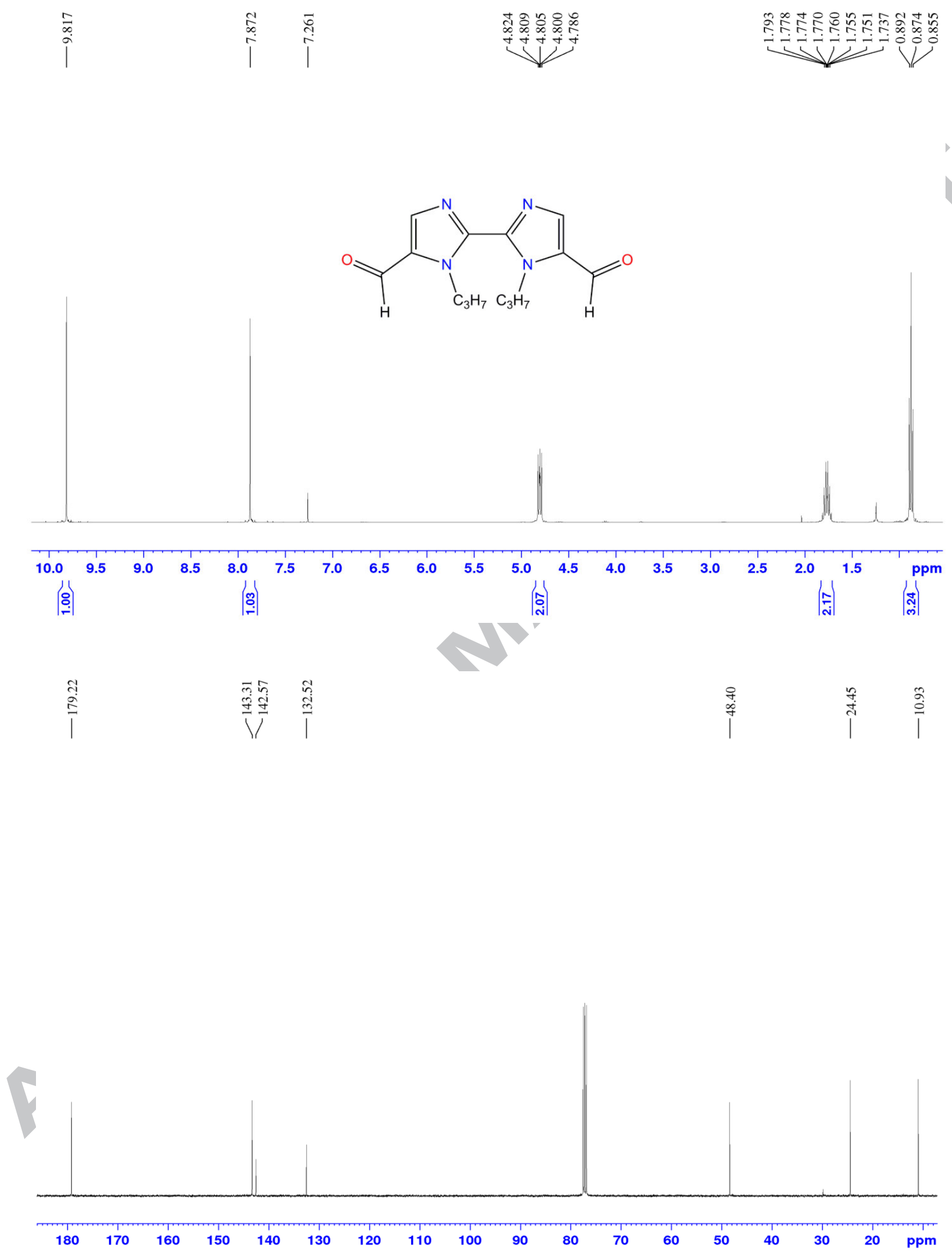

Figure S6. ${ }^{1} \mathrm{H}$ NMR (top) and ${ }^{13} \mathrm{C}$ NMR (bottom) spectra of Df-Pr 2 biim in $\mathrm{CDCl}_{3}$. 
$\prod_{\substack{0 \\ 0}}^{\infty}$

$\underbrace{}_{\substack{0 \\ \infty}}$

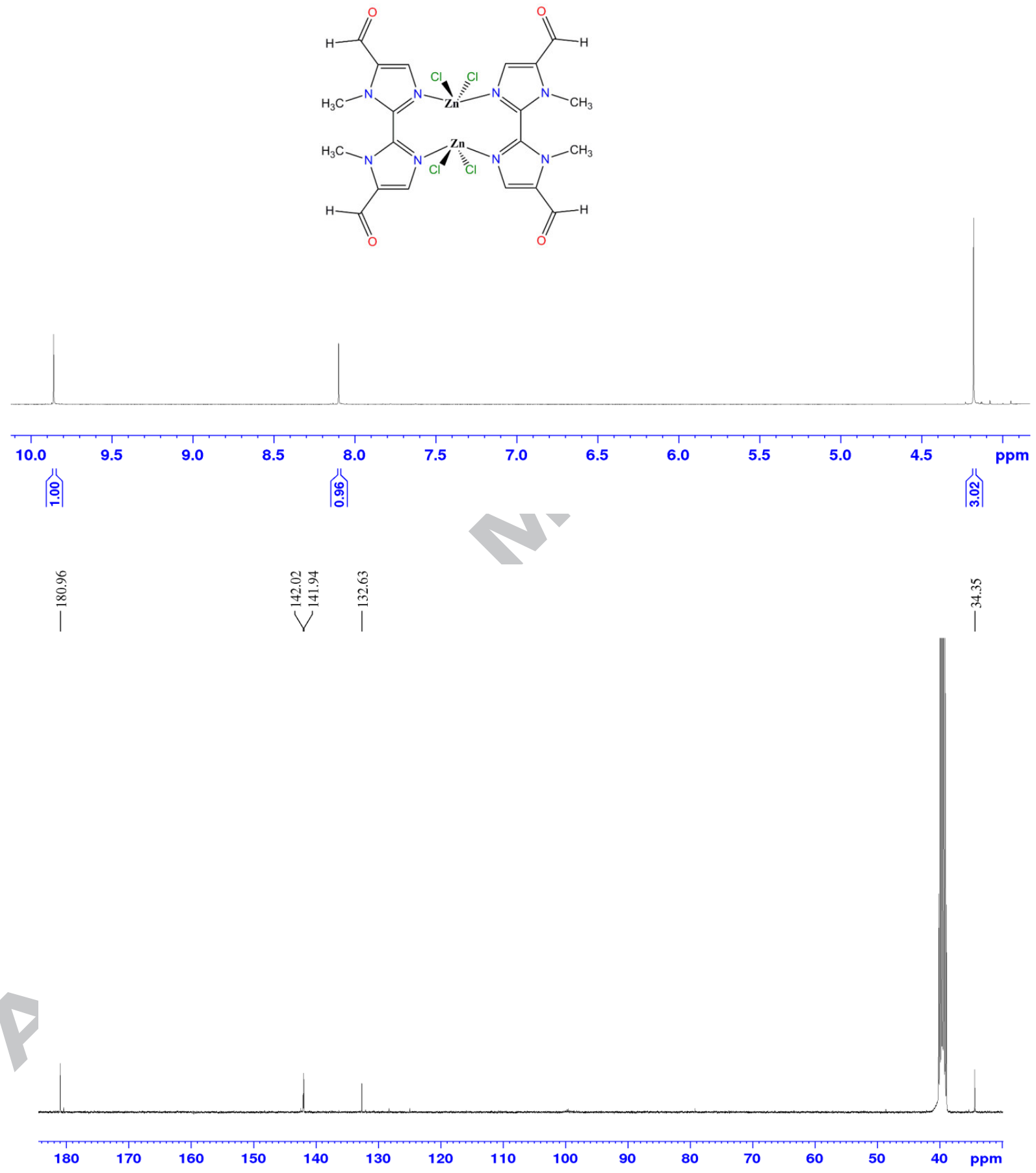

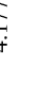

Figure S7. ${ }^{1} \mathrm{H}$ NMR (top) and ${ }^{13} \mathrm{C}$ NMR (bottom) spectra of 1a in DMSO-d6. 


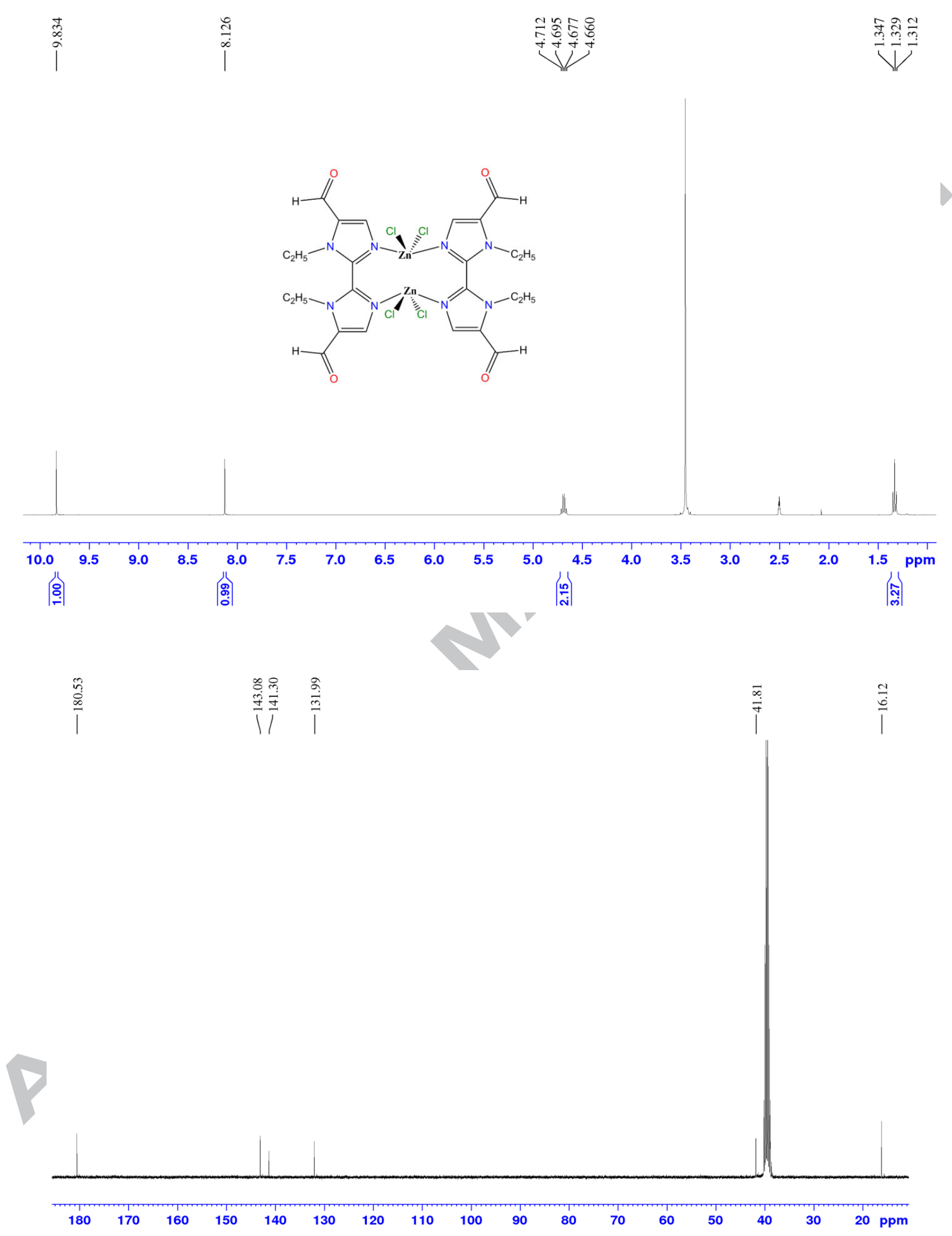

Figure S8. ${ }^{1} \mathrm{H}$ NMR (top) and ${ }^{13} \mathrm{C}$ NMR (bottom) spectra of $\mathbf{1 b}$ in DMSO-d6. 


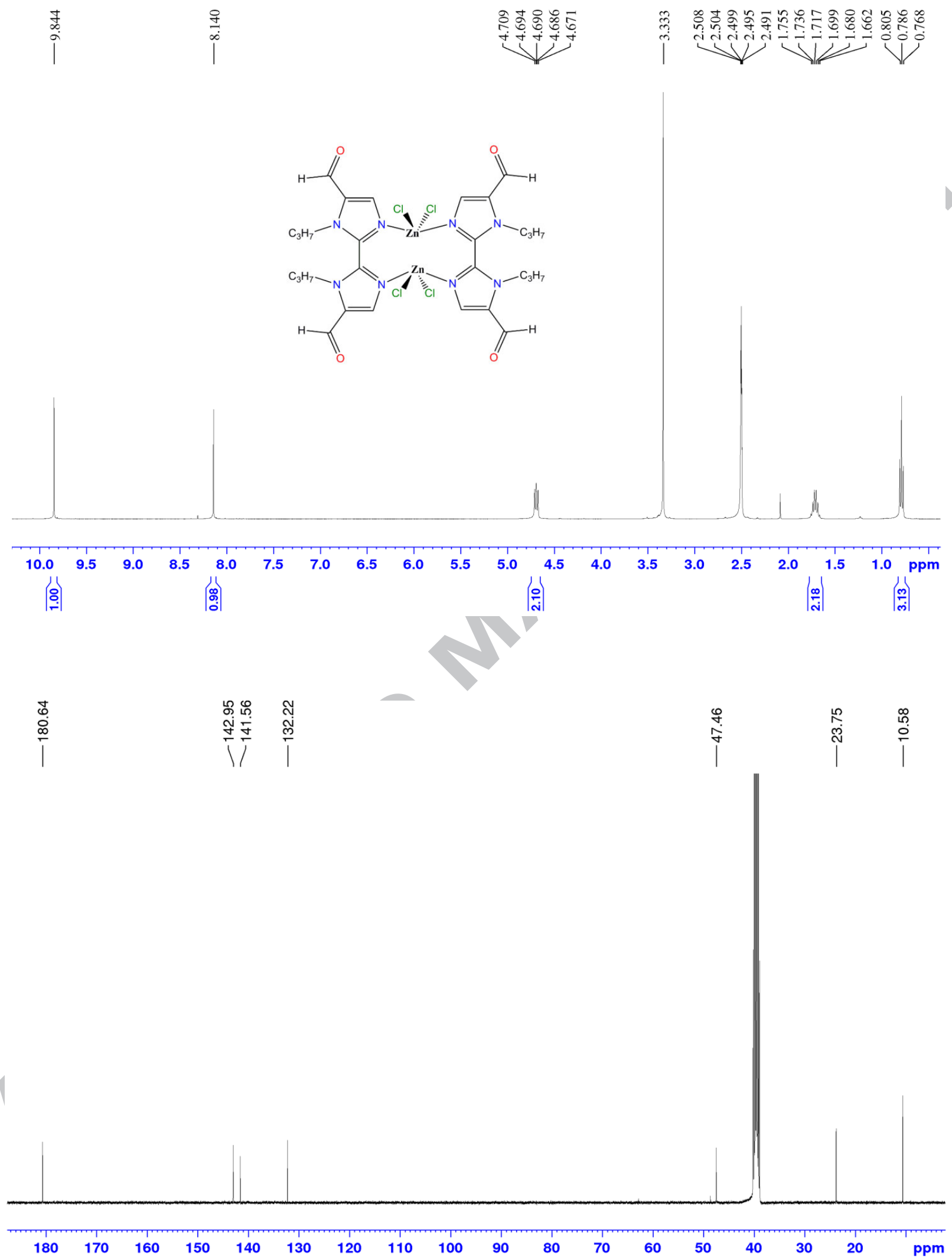

Figure S9. ${ }^{1} \mathrm{H}$ NMR (top) and ${ }^{13} \mathrm{C}$ NMR (bottom) spectra of 1c in DMSO-d6. 


\section{ACCEPTED MANUSCRIPT}

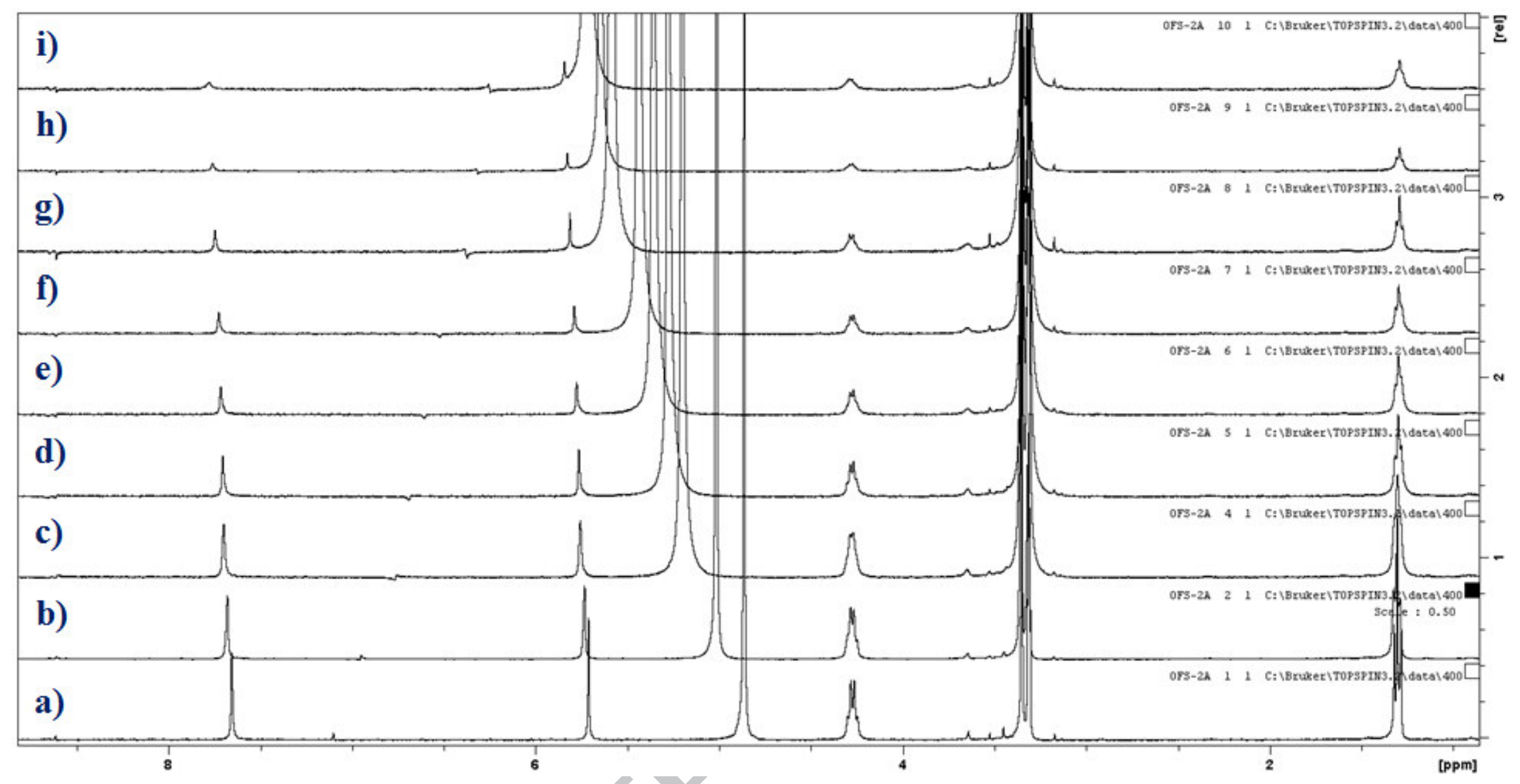

Figure S10. Variable temperature ${ }^{1} \mathrm{H}$ NMR spectra of $2 \mathbf{a}$ in $\mathrm{MeOD}-\mathrm{d} 4 .\left(25^{\circ} \mathrm{C}(\mathbf{a}), 0^{\circ} \mathrm{C}\right.$ to $-80^{\circ} \mathrm{C}(\mathbf{b}-\mathbf{i})$ with $10^{\circ} \mathrm{C}$ decreasing steps $)$. 


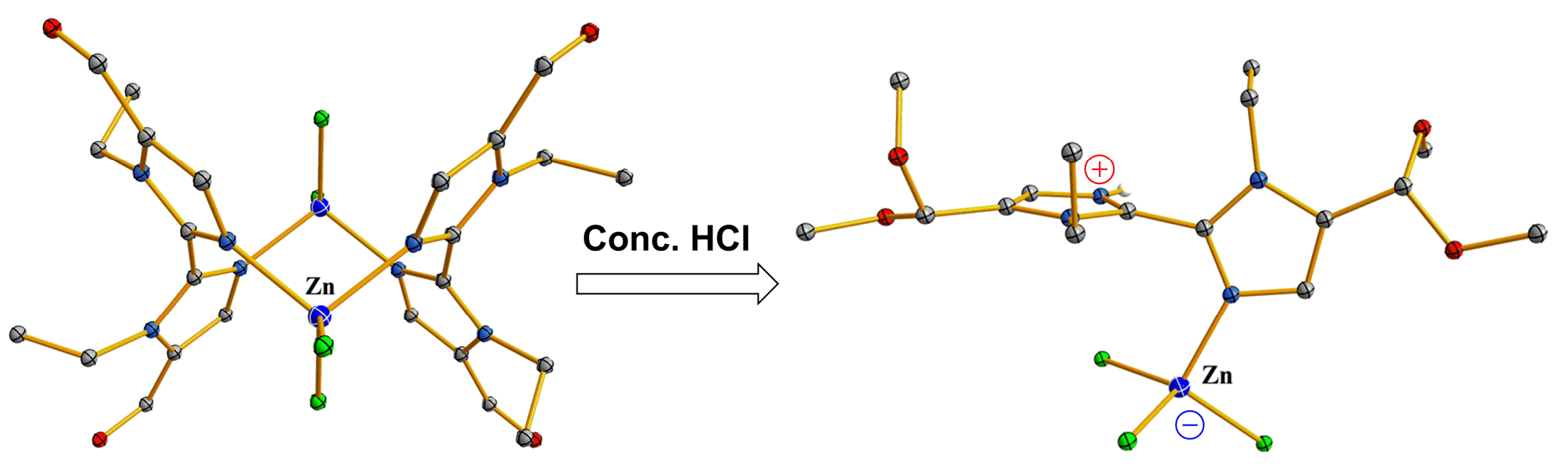




\section{Highlights}

Highly polar Zwitterionic coordination compounds of $\mathrm{Zn}$ and $\mathrm{Cu}$ have been synthesized by using ring and $\mathrm{N}$-substituted biimidazole ligands. The $\mathrm{Zwitterion}$ formation was found to be dependent on the acidity of the reaction media and the nature of the ligand substituents. 